\title{
1 Evaluation of Iron- and Manganese-based Mono- and Mixed-Metallic Oxygen \\ Carriers for Chemical Looping Combustion
}

\author{
Saurabh Bhavsar ${ }^{1,2}$, Brian Tackett ${ }^{1}$ and Götz Veser ${ }^{1,2, *}$ \\ ${ }^{1}$ Chemical Engineering Department, Swanson School of Engineering, University of Pittsburgh, \\ Pittsburgh, PA 15261 \\ ${ }^{2}$ U.S. Department of Energy - National Energy Technology Laboratory, Pittsburgh, PA
}

\section{Abstract:}

Chemical Looping Combustion (CLC) is an emerging technology for clean combustion of fossil fuels with inherent $\mathrm{CO}_{2}$ capture. In the present work, we investigate the use of iron and manganese based mixed oxides $\left(\mathrm{Mn}_{\mathrm{x}} \mathrm{Fe}_{1-\mathrm{x}}-\mathrm{CeO}_{2}\right)$ supported on $\mathrm{CeO}_{2}$ as oxygen carriers in CLC. The low cost and low toxicity of iron and manganese make them interesting candidates for CLC, but both mono-metallic carriers suffer from issues of low reactivity, and manganese is additionally prone to form undesired spinel structures with typical oxide supports. Mono- and bimetallic oxygen carriers were synthesized across the entire spectrum of compositions from pure $\mathrm{Mn}$ to pure $\mathrm{Fe}$ (with $\mathrm{x}=0,0.1,0.33,0.5,0.8,0.9,1$ ), characterized, and tested in thermogravimetric and fixed-bed reactor studies using $\mathrm{H}_{2}$ and $\mathrm{CH}_{4}$ as fuels. We find that the use of ceria as support results in stable operation for all compositions of the metal phase, including pure Mn. Bimetallic carriers with high Fe content, which contain a $\mathrm{FeMnO}_{3}$ phase, exhibit an unusual, reversible de-alloying/re-alloying behavior during cyclic redox operation, which precludes any synergistic effects between the two metals and results in slowed reduction kinetics. However, Mn-rich carriers show a pronounced increase in carrier reactivity and selectivity for

\footnotetext{
* Corresponding Author: Prof. Götz Veser (gveser@pitt.edu)
} 
23 total oxidation of methane due to the addition of small amounts of Fe, indicating the promise of 24 appropriately designed FeMn carriers as low-cost, environmentally benign oxygen carrier 25 materials for chemical looping combustion.

26

27 Keywords: Chemical looping combustion, $\mathrm{CO}_{2}$ capture, iron, manganese, mixed oxides, ceria. 


\section{Introduction:}

29 The development of technologies that allow for clean combustion of fossil fuels with efficient and affordable $\mathrm{CO}_{2}$ capture is necessary to enable their continued use as a primary source of energy until cost-competitive alternate energy sources are ready for wide-spread deployment.

32 Chemical Looping Combustion (CLC) is one of the most promising of these emerging 33 technologies, offering a highly efficient route for clean combustion of fossil fuels with inherent $34 \mathrm{CO}_{2}$ capture $^{1-3}$. In CLC, an oxygen carrier (typically a metal oxide) is contacted with fuel in the 35 first reactor (fuel reactor), undergoing reduction while providing necessary oxygen for the required combustion of the fuel (Figure 1). After combustion, the reduced metal is transferred to

37 the second reactor (air reactor) where it is re-oxidized in contact with air. The oxidized metal is 38 then circulated back to the fuel reactor, closing the materials 'loop'. In the fuel reactor, ideally a 39 pure mixture of $\mathrm{CO}_{2}$ and $\mathrm{H}_{2} \mathrm{O}$ is formed as combustion gases, from which high-concentration, 40 sequestration ready $\mathrm{CO}_{2}$ streams can be readily obtained via condensation of steam. Thus, CLC 41 offers a unique and efficient route for $\mathrm{NO}_{x}$-lean, flameless combustion of fossil fuels with 42 inherent $\mathrm{CO}_{2}$ capture at minimal efficiency penalty for $\mathrm{CO}_{2}$ capture, making it rather unique 43 among current and emerging $\mathrm{CO}_{2}$ capture technologies ${ }^{4-7}$.

44 Although the concept has been demonstrated widely ${ }^{8-13}$, there is still room for improvement in 45 the design of efficient oxygen carriers with sufficient carrier stability and fast redox kinetics as 46 key issues. Depending on the reactor configuration used for CLC, continuous cycling of particles 47 between reduced and oxidized states subjects the oxygen carriers to chemical, thermal and - in 48 transport reactor configurations - mechanical stress. Consequently, vast efforts have been made to develop efficient oxygen carriers that can cope with the harsh environment of CLC. Most of 50 the oxygen carriers reported in the literature are synthetic carrier materials. $\mathrm{Cu}-, \mathrm{Ni}-, \mathrm{Fe}-, \mathrm{Mn}-$, 
51 and Co-based oxygen carriers have been investigated to evaluate their thermal stability and

52 reactivity ${ }^{14-18}$, with the active metal typically rendered thermally stable by supporting them on

53 inert oxides such as $\mathrm{Al}_{2} \mathrm{O}_{3}, \mathrm{SiO}_{2}, \mathrm{ZrO}_{2}$, and $\mathrm{MgAl}_{2} \mathrm{O}_{4}{ }^{19-24}$.

54 Among the various metals tested for CLC, iron has recently emerged as an attractive candidate

55 due to its low toxicity, low cost and abundance. However, its poor reactivity with typical fuels

56 and limited oxygen transfer capacity (due to the limitation to the $\mathrm{Fe}_{2} \mathrm{O}_{3} \Leftrightarrow \mathrm{Fe}_{3} \mathrm{O}_{4}$ transition at

57 typical CLC operating conditions) necessitates a high solid inventory. Beyond iron, manganese

58 constitutes another environmentally benign and low cost metal which has been identified as

59 possible oxygen carrier. Like iron, it also exhibits multiple oxidation states that could be

60 potentially utilized for total oxidation of fuel. However, despite this, only few studies have to-

61 date investigated the use of Mn-based oxygen carriers, and those studies have found low

62 reactivity and tendency to react with support oxides to form stable spinels to be limiting for the

63 use of $\mathrm{Mn}$ in oxygen carriers for chemical looping ${ }^{18-19,23}$.

64 We have previously shown that combining low-reactivity iron with highly active nickel through

65 the use nickel ferrites, can improve the carrier reactivity ${ }^{25}$. In the present work, we are extending

66 this approach towards investigating the effect of combining iron with manganese - a non-toxic

67 and significantly cheaper alternative to nickel. Fe-Mn system would thus constitute low cost,

68 environmentally benign carrier materials. Moreover, both metals naturally occur together in

69 number of ores and minerals, making them of interest not only for engineered carrier materials

70 but also potentially for use as natural ores.

71 The Fe-Mn system has been studied before, although almost exclusively in the context of so-

72 called chemical looping oxygen uncoupling (CLOU) in which the combustion of the fuel does

73 not occur in a direct reaction with the lattice oxygen of the carrier, but rather with gaseous 
oxygen that is released from the carrier at the conditions of the fuel reactor. The FeMn system 75 promises favorable thermodynamics for gas phase oxygen release according to $6(\mathrm{Mn}, \mathrm{Fe})_{2} \mathrm{O}_{3}=$ $764(\mathrm{Mn}, \mathrm{Fe})_{3} \mathrm{O}_{4}+\mathrm{O}_{2}(\mathrm{~g}),{ }^{26}$ as confirmed experimentally ${ }^{27-29}$. Among a range of Mn bimetallics 77 tested, including $\mathrm{Mn}-\mathrm{Mg}, \mathrm{Mn}-\mathrm{Ni}, \mathrm{Mn}-\mathrm{Si}$ and $\mathrm{Mn}-\mathrm{Fe}$, mixed oxides of iron and manganese were 78 found to show good oxygen release characteristics ${ }^{30-31}$, but in-situ X-ray studies of the phase 79 evolution during reduction and re-oxidation of FeMn carriers indicated phase segregation during 80 reduction $^{32}$.

81 In contrast to those previous studies, the present contribution is focused on the investigation of 82 Fe-Mn carriers for "conventional" CLC applications, i.e. for conditions where lattice oxygen 83 rather than "uncoupled" gas phase oxygen is utilized for the combustion of the fuel. Towards this 84 purpose, we specifically synthesized Fe-Mn carriers over the entire range of Fe:Mn ratios in order to identify the impact of this ratio on the stability and activity of these carriers in CLC.

86 However the Fe-Mn bimetallic system has been shown to undergo de-alloying during redox 87 operation $^{32}$, and such phase segregation would eliminate any possibility of synergistic effects 88 between the two metals. Based on our previous work which showed that the use of reducible 89 oxides as active supports can not only strongly enhance the redox kinetics of oxygen carriers ${ }^{33}$ 90 but also strongly enhance phase stability of supported bimetallic nickel ferrite carriers, ${ }^{25}$ we 91 therefore again utilize ceria as support for the Fe-Mn phases with aim of obtaining stable FeMn 92 bimetallic carriers with improved thermal and redox stability. All carriers are synthesized by 93 simple incipient wetness and characterized to identify the bimetallic phases formed. With this 94 understanding, the $\mathrm{Mn}_{\mathrm{x}} \mathrm{Fe}_{1-\mathrm{x}}-\mathrm{CeO}_{2}$ carriers are then subjected to $\mathrm{CLC}$ tests using $\mathrm{H}_{2}$ and $\mathrm{CH}_{4}$ as 95 fuels in a thermogravimetric analyzer (TGA) to characterize the solid phase kinetics and then 96 further investigated in fixed-bed reactor tests to analyze gas phase (fuel) conversion and 
97 selectivity. The combination of these investigations, allows us to obtain a rather complete picture 98 of the stability, activity, and selectivity of Fe-Mn carrier materials for CLC applications.

\section{Experimental Section:}

\subsection{Oxygen Carrier Synthesis:}

102 Synthesis of oxygen carriers using low-cost, scalable techniques is critical in limiting the cost of 103 oxygen carrier manufacturing. Thus, in this study oxygen carriers were synthesized in a simple and scalable two-step procedure. First the ceria support was synthesized in a hydrothermal synthesis, and $\mathrm{Fe}$ and $\mathrm{Mn}$ were deposited by incipient wetness technique.

$\mathrm{CeO}_{2}$ was prepared by a facile hydrothermal synthesis procedure previously adapted in our

research group ${ }^{34}$ and used before for the synthesis of $\mathrm{Ni}$ and FeNi based oxygen carriers ${ }^{25,} 33$. Briefly, $0.752 \mathrm{~g}$ of $\mathrm{Ce}\left(\mathrm{NO}_{3}\right)_{3} \cdot 6 \mathrm{H}_{2} \mathrm{O}(99+\%$, Sigma-Aldrich) were dissolved in $8 \mathrm{ml}$ DI water. 30 $\mathrm{ml}$ of $\mathrm{NaOH}(98+\%$, Sigma-Aldrich) solution $(7 \mathrm{M})$ was rapidly added under vigorous stirring. After $30 \mathrm{~min}$ of stirring, the slurry was transferred into a $50 \mathrm{ml}$ autoclave, heated to $100^{\circ} \mathrm{C}$ under autogenous pressure for $72 \mathrm{~h}$, and then allowed to cool to room temperature. The product was washed with DI water and collected via centrifugation to remove any ionic remnants until the $\mathrm{pH}$ 113 of the solution was 7 . After drying the powders at $100^{\circ} \mathrm{C}$ overnight and calcination at $450^{\circ} \mathrm{C}$ for 2 $114 \mathrm{~h}$, the final product was obtained.

115 Mixed oxides of iron and manganese $\left(\mathrm{Mn}_{\mathrm{x}} \mathrm{Fe}_{1-\mathrm{x}}-\mathrm{CeO}_{2}\right)$ with 40 wt.\% FeMn weight loadings were 116 synthesized by simple incipient wetness technique. $\mathrm{Mn}_{\mathrm{x}} \mathrm{Fe}_{1-\mathrm{x}}-\mathrm{CeO}_{2}$ carriers with $\mathrm{x}=0,0.1,0.33$,

$1170.5,0.8,0.9$, and 1, i.e. with compositions ranging across the entire spectrum from pure Mn to 118 pure $\mathrm{Fe}$, were prepared to investigate the effect of the $\mathrm{Fe} / \mathrm{Mn}$ ratio on carrier reactivity and 119 selectivity towards total oxidation of methane. Briefly, the appropriate amount of the respective 
120 metal nitrates $\left(\mathrm{Fe}\left(\mathrm{NO}_{3}\right)_{3} \cdot 9 \mathrm{H}_{2} \mathrm{O}\right.$ and $\mathrm{Mn}\left(\mathrm{NO}_{3}\right)_{2} \cdot 4 \mathrm{H}_{2} \mathrm{O}$, both $99+\%$, Sigma-Aldrich) were dissolved

121 in $1 \mathrm{~mL}$ ethanol (200 proof, Decon Labs, Inc.) to obtain a clear solution. $200 \mathrm{mg}$ of support

122 material was added and stirred for $2 \mathrm{~h}$. The obtained slurry was dried in a vacuum oven at $80^{\circ} \mathrm{C}$

123 overnight, and calcined at $900^{\circ} \mathrm{C}$ for $2 \mathrm{~h}$ to obtain the final form of the oxygen carrier.

\subsection{Oxygen Carrier Characterization:}

125 The carriers were thoroughly characterized at different stages of the experiments, i.e. after

126 synthesis, after reactive tests in TGA, and after fixed-bed reactor tests. The specific surface area

127 was determined via nitrogen sorption in a Micromeritics ASAP 2020 gas adsorption analyzer

128 using the BET method. Prior to the measurement, the samples were degassed for $2 \mathrm{~h}$ at $200^{\circ} \mathrm{C}$

129 under high vacuum. After calcination at $900^{\circ} \mathrm{C}$ for $2 \mathrm{~h}$, all the carriers had a surface area $<5 \mathrm{~m}^{2} / \mathrm{g}$

130 as expected due to initial sintering of carriers due to the relatively low thermal stability of ceria

131 as support ${ }^{35-38}$.

132 X-ray diffraction (XRD) measurements were performed with a powder X-ray diffractometer

133 (Phillips PW1830) in line focus mode employing $\mathrm{Cu} \mathrm{K} \alpha$ radiation $(\lambda=1.5418 \AA$ ) with typical $2 \theta$

134 scans between $15^{\circ}$ and $90^{\circ}$. Crystal phases were identified based on JCPDS cards. Average 135 crystal lattice spacings were determined using Bragg's law.

136 A JEOL JEM-2100F high-resolution transmission electron microscope (HR-TEM) was used to 137 obtain TEM images and conduct electron energy-loss spectroscopy (EELS) to determine 138 spatially resolved local elemental composition in the sample.

\subsubsection{Thermogravimetric Analyzer (TGA) Tests:}


142 Pure $\mathrm{H}_{2}$ was used as a model fuel for initial characterization of the carrier performance during 143 redox cycles without the added complexity of carbon formation that is associated with use of 144 methane as fuel. Kinetics and thermal stability of the carriers with $\mathrm{H}_{2}$ as fuel were evaluated in 145 thermogravimetric analyzer tests (Perkin Elmer TGA-7). Subsequently, CLC redox cycles were 146 conducted (TA instruments, SDTQ600) with $\mathrm{CH}_{4}$ as fuel to test for carrier selectivity and 147 thermal stability with a particular focus on carbon formation on the carrier material that would 148 result in undesired carbon carry-over from the reducer to the oxidizer.

149 In a typical run, up to $15 \mathrm{mg}$ of oxygen carriers were heated inside the TGA cradle in an inert gas 150 stream $\left(\mathrm{N}_{2}\right.$ or Ar, Grade 5.0) to the desired reaction temperature of $900^{\circ} \mathrm{C}$. Then, $\mathrm{H}_{2}$ (Grade 5.0) 151 and air (Grade 0.1) were fed alternatingly at a flowrate of $20 \mathrm{sccm}$ to simulate the periodic 152 reduction-oxidation cycles of CLC. Between reduction and oxidation phases, the TGA was 153 purged with $\mathrm{N}_{2}$ or $\operatorname{Ar}(20 \mathrm{sccm}$, Grade 5.0) to avoid formation of potentially flammable gas 154 mixtures inside the instrument. In $\mathrm{CLC}$ with $\mathrm{CH}_{4}$ as fuel (Grade 2.0, $5 \mathrm{sccm}$ ), suitable reduction 155 times were determined by varying the duration of the reduction half cycle and the $\mathrm{CH}_{4}$ flowrate 156 while monitoring the occurrence of carbon burn-off in the oxidation half cycle. All other 157 experimental conditions were identical as above for $\mathrm{H}_{2} .5$ - 10 redox cycles were conducted in 158 the TGA experiments in order to identify any obvious onset of deactivation of the oxygen carrier. 159 All experiments were conducted at ambient pressure conditions.

\subsubsection{Fixed-bed Reactor tests:}

162 Oxygen carriers were evaluated in a fixed-bed reactor to investigate their reactivity in converting 163 methane into steam and carbon dioxide. $100 \mathrm{mg}$ of $\mathrm{Mn}_{\mathrm{x}} \mathrm{Fe}_{1-\mathrm{x}}-\mathrm{CeO}_{2}$ powder was placed inside the 164 quartz-glass tubular reactor (1/4" ID), which was inserted into an electric oven (Thermo Electron 
165 Corporation - Lindberg/Blue M). A coking resistant high temperature stable thermocouple was

166 inserted into the carrier bed to measure the actual bed temperature. The oven was heated to

$167900^{\circ} \mathrm{C}$, and $\mathrm{CH}_{4}\left(1 \mathrm{sccm}\right.$, Grade $2.0,16.7 \mathrm{vol} \%$ in $\left.\mathrm{Ar}, \mathrm{GHSV} \sim \mathbf{2 2 7 4} \mathbf{h}^{\mathbf{- 1}}\right)$ and $\mathrm{O}_{2}(20 \mathrm{sccm}$,

$16820 \mathrm{vol} \%$ in $\mathrm{He}$ ) were flown alternatingly to simulate the periodic reduction and oxidation in CLC.

169 Depending on the reactivity of the various FeMn carriers, reduction times in FBR varied

170 from 10 to $45 \mathrm{~min}$, while the oxidation half cycle was conducted for $10 \mathrm{~min}$ to fully

171 regenerate the carriers and observe complete oxygen break-through. In between reduction

172 and oxidation of the carrier, the reactor was again purged with argon (Grade 5.0) to avoid

173 formation of explosive mixtures of air and $\mathrm{CH}_{4}$ inside the reactor. After condensation of

174 moisture, the effluent gases were recorded using a mass spectrometer (Pfeiffer Omnistar QMS

$175200)$ and from these measurements molar flowrates $\left(n_{i}\right)$ were determined for all species observed

176 during the reaction. A carbon balance was performed at all measurements to assure the accuracy

177 of the analysis and closed within 5-10\% error for all reported experiments.

178 Carbon Balance:

$179 n_{\mathrm{CH}_{4, \text { in }}}=n_{\mathrm{CH}_{4, \mathrm{out}}}+n_{\mathrm{CO}_{2, \mathrm{out}}}+n_{\mathrm{CO}_{\text {out }}}+n_{\text {solid carbon }}$

180

$n_{\mathrm{CH}_{4, \text { in }}}=n_{\mathrm{CH}_{4, \mathrm{out}}}+n_{\mathrm{CO}_{2, \mathrm{out}}}+n_{\mathrm{CO}_{\text {out }}}+0.5 \times\left(n_{\mathrm{H}_{2, \mathrm{out}}}-2 n_{\mathrm{CO}_{\text {out }}}\right)$

181 On-stream methane conversion $\left(\mathrm{X}_{\mathrm{CH} 4}\right)$ and cumulative carrier $\left(\mathrm{X}_{\text {carrier }}\right)$ conversion were 182 calculated according to:

$183 X_{\mathrm{CH}_{4}}=\frac{n_{\mathrm{CH}_{4, \text { in }}}-n_{\mathrm{CH}_{4, \text { out }}}}{n_{\mathrm{CH}_{4, \text { in }}}}, X_{\text {Carrier }}=\frac{4 \sum n_{\mathrm{CO}_{2, \text { out }}}+\sum n_{C O_{, \text {out }}}}{\text { Total mol of O in carrier }}$ 
184 Selectivity of various species $\left(\mathrm{S}_{\mathrm{i}}\right)$ viz. $\mathrm{CO}_{2}, \mathrm{H}_{2}, \mathrm{CO}$ and carbon $(\mathrm{C})$ formation by methane 185 pyrolysis were calculated according to the following equations:

186

$S_{\mathrm{CO}_{2}}=\frac{n_{\mathrm{CO}_{2, \mathrm{out}}}}{\left(n_{\mathrm{CH}_{4, \text { in }}}-n_{\mathrm{CH}_{4, \text { out }}}\right)}, S_{\mathrm{CO}}=\frac{n_{\mathrm{CO}_{\text {out }}}}{\left(n_{\mathrm{CH}_{4, \text { in }}}-n_{\mathrm{CH}_{4, \mathrm{out}}}\right)}$

187

$S_{H_{2}}=\frac{0.5 n_{H_{2, \text { out }}}}{\left(n_{C H_{4, \text { in }}}-n_{C H_{4, \text { out }}}\right)}, S_{\text {Carbon }}=\frac{0.5\left(n_{H_{2, \text { out }}}-2 n_{C O_{\text {out }}}\right)}{\left(n_{C H_{4, \text { in }}}-n_{C H_{4, \text { out }}}\right)}$
188

190

191

192

193

194

195

196

197

As expected, total oxidation, partial oxidation and catalytic pyrolysis of methane are the dominant reactions occurring in the system at all experimental conditions, which are shown below for a generic oxygen carrier, where "MeO" is metal oxide and "Me" is the reduced metal:

$$
\text { Total Oxidation: } \quad \mathrm{CH}_{4}+4 \mathrm{MeO} \Leftrightarrow 4 \mathrm{Me}+\mathrm{CO}_{2}+2 \mathrm{H}_{2} \mathrm{O}
$$

Partial Oxidation: $\quad \mathrm{CH}_{4}+\mathrm{MeO} \Leftrightarrow \mathrm{Me}+\mathrm{CO}+2 \mathrm{H}_{2}$

Methane Pyrolysis: $\quad \mathrm{CH}_{4}(+\mathrm{Me}) \Leftrightarrow 2 \mathrm{H}_{2}+\mathrm{C}(+\mathrm{Me})$

\section{Results and Discussion:}

\subsection{Formation of Bimetallic Phases and Phase Stability:}

Understanding the structural properties of oxygen carriers is important to confidently establish structure-activity relationships. In the context of Chemical Looping Oxygen Uncoupling (CLOU), the ability to release oxygen of mixed metal oxides of iron and manganese were shown to have strong dependence on the Fe/Mn ratio. However, powder XRD results were inconclusive to determine the exact composition of monometallic and bimetallic phase ${ }^{27,30}$. Hence, a primary 
202 aim of the present study was the investigation of the effect of the Fe/Mn ratio on carrier phase 203 composition, phase stability, and its impact on performance in CLC redox cycles. Therefore, all 204 oxygen carriers were carefully characterized to identify any bimetallic Fe-Mn phases present and 205 their impact on the carrier reactivity in CLC redox cycles.

$206 \mathrm{Mn}_{\mathrm{x}} \mathrm{Fe}_{1-\mathrm{x}}-\mathrm{CeO}_{2}$ carriers with $\mathrm{x}=0,0.1,0.33,0.5,0.8,0.9$, and 1, i.e. with compositions ranging 207 across the entire range from pure Fe to pure Mn were synthesized and characterized. The phase 208 diagram of binary Fe-Mn oxides in air is fairly well established and shows that $\mathrm{Fe}_{2} \mathrm{O}_{3}$ and $\mathrm{Mn}_{2} \mathrm{O}_{3}$ 209 exhibit mutual solubility up to temperatures of approximately $1000^{\circ} \mathrm{C}^{26}$. Depending on the 210 Fe:Mn ratio, Fe-Mn binary systems form a spinel solid solution $\left(\mathrm{Fe}_{3} \mathrm{O}_{4}-\mathrm{Mn}_{3} \mathrm{O}_{4}\right)$ with a 1:1 ratio 211 of Fe and Mn, a mostly hematite containing solid solution at the Fe-rich end $\left(\mathrm{Fe}_{2} \mathrm{O}_{3}\right.$ with a small 212 amount of manganese oxide dissolved in it), and, for Mn-rich compositions, $\mathrm{Mn}_{2} \mathrm{O}_{3}$ or $\mathrm{Mn}_{3} \mathrm{O}_{4}$ 213 rich solid solutions (depending on temperature either $\alpha-\mathrm{Mn}_{2} \mathrm{O}_{3}$ or $\mathrm{Mn}_{3} \mathrm{O}_{4}$ with a small amount of 214 dissolved iron oxide $)^{26}$. Thus, the literature data confirms that iron and manganese show high 215 affinity towards each other which can result in formation of various bimetallic phases, depending 216 on their relative concentrations.

217 Figure 2 shows the x-ray diffraction pattern of $\mathrm{Mn}_{\mathrm{x}} \mathrm{Fe}_{1-\mathrm{x}}-\mathrm{CeO}_{2}$ oxygen carriers subjected to 218 calcination in air at $900^{\circ} \mathrm{C}$ for $2 \mathrm{~h}$. For pure $\mathrm{Mn}-\mathrm{CeO}_{2}$ (figure 2a), only peaks corresponding to $219 \mathrm{Mn}_{2} \mathrm{O}_{3}$ and $\mathrm{CeO}_{2}$ are detected with no signs of the formation of a spinel phase between manganese oxide and ceria. Manganese has been reported to have a strong tendency to react with 221 oxide supports forming spinel structures that are inactive for further redox cycles ${ }^{19}$. Absence of 222 such spinels with ceria as support thus confirms the excellent suitability of ceria as support in 223 oxygen carriers, in agreement with our previous report that ceria plays a key role in stabilizing $224 \mathrm{Fe}, \mathrm{Ni}$ and $\mathrm{NiFe}_{2} \mathrm{O}_{4}{ }^{25,33}$. Upon doping some iron into manganese oxide (figure $2 \mathrm{~b}, \mathrm{c}$ ), no separate 
225 peaks of $\mathrm{Fe}_{2} \mathrm{O}_{3}$ are observed, indicating that iron is well dispersed in the $\mathrm{Mn}_{2} \mathrm{O}_{3}$ structure. With a 226 further increase in $\mathrm{Fe}$ to a equimolar ratio of $\mathrm{Mn}: \mathrm{Fe}$, the bimetallic bixbyite phase $\left(\mathrm{FeMnO} \mathrm{O}_{3}\right)$ is 227 observed (figure 2d). Fe-rich carriers (Fe:Mn > 1) shows the appearance of a $\mathrm{Fe}_{2} \mathrm{O}_{3}$ phase in 228 addition to bixbyite (figure 2e). Such behavior has been observed before with ball milled 229 samples $^{39}$. Finally, bimetallic carriers with only $10 \%$ Mn show only diffractions corresponding to $230 \mathrm{Fe}_{2} \mathrm{O}_{3}$ (figure 2f), suggesting the absence of a bixbyite phase and the dispersion of $\mathrm{Mn}_{2} \mathrm{O}_{3}$ in the 231 predominant hematite phase.

232 While information of nominal weight loadings of iron and manganese coupled with detection of 233 the above discussed phases allows for logical peak assignment in XRD analysis, determination of 234 relative quantities of $\mathrm{FeMnO}_{3}$ (JCPDS PDF \#: 76-0076) and $\mathrm{Mn}_{2} \mathrm{O}_{3}$ (JCPDS PDF \#: 78-0390) is 235 not possible, as both the bixbyite and hematite show identical diffraction patterns with almost 236 identical relative peak intensities. Below about $300 \mathrm{~K}, \alpha-\mathrm{Mn}_{2} \mathrm{O}_{3}$ transforms from a cubic to an 237 orthorhombic crystal structure ${ }^{40-41}$, while $\mathrm{FeMnO}_{3}$ exhibits cubic bixbyite phase ${ }^{42}$. However, 238 despite their different crystal structures at room temperature, distinguishing between $\mathrm{Mn}_{2} \mathrm{O}_{3}$ and $239 \mathrm{FeMnO}_{3}$ by means of lattice parameters is not possible, as they exhibit near identical values ${ }^{41-42}$. 240 However, verification of the formation of the bimetallic phase is critical to understand their 241 reactivity in redox cycles.

242 Therefore, $\mathrm{Mn}_{0.5} \mathrm{Fe}_{0.5}-\mathrm{CeO}_{2}$ - i.e. a bimetallic carrier with equimolar amounts of iron and 243 manganese - was chosen for further tests to confirm the successful formation of the bimetallic $244 \mathrm{FeMnO}_{3}$ phase. $\mathrm{Mn}_{0.5} \mathrm{Fe}_{0.5}-\mathrm{CeO}_{2}$ was chosen due to the ease of analysis as complete 245 incorporation of one metal into the equimolar amount of the other would only form $\mathrm{FeMnO}_{3}$ and 246 would not result in the formation of a separate monometallic $\mathrm{Fe}_{2} \mathrm{O}_{3}$ phase. Calcination 247 temperature variation was chosen as test parameter: As-synthesized powders were first calcined 
248 at $800^{\circ} \mathrm{C}$ for $\mathrm{x}$-ray analysis, and subsequently calcined at the CLC operation temperature of $249900^{\circ} \mathrm{C}$. Figure 3 shows the XRD pattern of $\mathrm{Mn}_{0.5} \mathrm{Fe}_{0.5}-\mathrm{CeO}_{2}$ after calcination at a) $800^{\circ} \mathrm{C}$ and b) $250900^{\circ} \mathrm{C}$. It can be seen that the carrier calcined at $800^{\circ} \mathrm{C}$ clearly displays the presence of free $251 \mathrm{Fe}_{2} \mathrm{O}_{3}$ phase in the sample, whereas the peaks corresponding to $\mathrm{Fe}_{2} \mathrm{O}_{3}$ disappear upon calcination 252 of sample at $900^{\circ} \mathrm{C}$. Thus, absence of $\mathrm{Fe}_{2} \mathrm{O}_{3}$ diffraction peaks strongly suggests that all the iron 253 oxide is incorporated into the cubic bixbyite structure of $\mathrm{FeMnO}_{3}$, and if there is any residual 254 free iron oxide present in the sample, it is under the detection limit of the XRD analysis.

255 Furthermore, TEM equipped with electron energy loss spectroscopy (EELS) was used to 256 understand the spatial distribution of the metals at the nanometer scale. Figure 4 shows a typical 257 TEM and elemental maps of $\mathrm{Mn}, \mathrm{Fe}$ and $\mathrm{Ce}$ in the $\mathrm{Mn}_{0.5} \mathrm{Fe}_{0.5}-\mathrm{CeO}_{2}$ sample. It can be observed 258 that iron and manganese are well dispersed in the sample, and they are found in close vicinity of 259 each other. No separate islands of iron (i.e. devoid of manganese) could be found. Thus EELS 260 analysis is in agreement with the formation of $\mathrm{FeMnO}_{3}$ in the $\mathrm{Mn}_{0.5} \mathrm{Fe}_{0.5}-\mathrm{CeO}_{2}$ sample.

261 Finally, Rietveld refinement was performed as an auxiliary test using the commercially available 262 software PANalytical X'Pert Highscore Plus to determine quantitative phase composition of $263 \mathrm{Mn}_{0.5} \mathrm{Fe}_{0.5}-\mathrm{CeO}_{2}$. The required high resolution data was obtained by powder diffraction 264 measurements using a Brukers D8 Discover, equipped with LynxEye Detector. Rietveld analysis 265 resulted in good fitting, and the $\mathrm{Mn}_{0.5} \mathrm{Fe}_{0.5}-\mathrm{CeO}_{2}$ sample was found to contain $42.6 \% \mathrm{FeMnO}_{3}$, $2660.2 \% \mathrm{Mn}_{2} \mathrm{O}_{3}, 0.4 \% \mathrm{Fe}_{2} \mathrm{O}_{3}$ and $56.8 \% \mathrm{CeO}_{2}$. Therefore Rietveld analysis also re-confirms that $267 \mathrm{FeMnO}_{3}$ is the major phase containing iron and manganese (with only minimal trace amounts of 268 free $\mathrm{Mn}_{2} \mathrm{O}_{3}$ and $\mathrm{Fe}_{2} \mathrm{O}_{3}$ ). Furthermore, the metal weight loading calculated is in close agreement 269 with the nominal weight loading of the carriers (40 wt.\%). 
270 Thus, having identified and confirmed the phase composition of the bimetallic oxygen carriers,

271 the carriers were next subjected to CLC redox cycles to investigate their reactive properties.

272

\section{3.2 Reactivity Tests in TGA:}

274 As a first reactive test, all carriers were investigated using thermogravimetric analysis (TGA) via

275 periodically exposing them to reducing $\left(\mathrm{H}_{2}\right.$ or $\left.\mathrm{CH}_{4}\right)$ and oxidizing (air) environments at $900^{\circ} \mathrm{C}$ in

276 order to test carrier stability, reactivity, and oxygen carrying capacity. Higher oxidation state

277 oxides of manganese (i.e., $\mathrm{MnO}_{2}$ and $\mathrm{Mn}_{2} \mathrm{O}_{3}$ ) are known to be thermally unstable at elevated

278 temperatures, i.e. depending on operating conditions like temperature and oxygen partial

279 pressure they thermally decompose to lower a oxidation state under the release of gaseous

280 oxygen $^{26}$. As discussed in the introduction, the mechanism of this oxygen release is a key

281 principle behind CLOU. However, this aspect has been studied in detail by the Chalmers group ${ }^{27-}$

$282^{30,43-50}$, and is not the focus of the present work. Instead, we avoid the complications of

283 simultaneous gas phase and gas-solid phase combustion reactions by choosing the operation

284 temperature of $900^{\circ} \mathrm{C}$ where $\mathrm{Mn}_{3} \mathrm{O}_{4}$ is the stable oxide in equilibrium with air ${ }^{26}$, i.e. the carriers

285 release excess oxygen upon the first heating to operating temperature and cannot be oxidized 286 beyond this oxidation state in subsequent redox cycles, hence avoiding any "oxygen uncoupling" 287 activity.

288 In the first stage of the experiments, hydrogen was used as the model fuel to avoid complications 289 due to undesired carbon formation. Following that, the carriers were exposed to redox cycles 290 using methane as fuel. 


\subsubsection{Reactivity Tests with Hydrogen as Fuel:}

293 All TGA tests were conducted at $900^{\circ} \mathrm{C}$ with carriers being reduced in $\mathrm{H}_{2}(10-30$ min) and then 294 oxidized in air $(10-15 \mathrm{~min})$, separated by a $\mathrm{N}_{2}$ purge in between the two half cycles. Figure 5 295 shows six redox cycles for a monometallic $\mathrm{Mn}-\mathrm{CeO}_{2}$ sample during cyclic operation with $\mathrm{H}_{2}$ and 296 air. The dotted lines in the figure depict the expected sample weight corresponding to various 297 oxidation states of manganese (calculated based on the metal weight loading). In the experiment, 298 the $\mathrm{Mn}_{2} \mathrm{O}_{3}-\mathrm{CeO}_{2}$ carrier was first heated to the operation temperature under an inert atmosphere 299 with $50^{\circ} \mathrm{C} / \mathrm{min}$ ramp rate. As expected and discussed above, the sample thermally decomposes during this heating phase, releasing oxygen and correspondingly losing weight, and the carrier weight eventually stabilizes at the weight corresponding to $\mathrm{Mn}_{3} \mathrm{O}_{4}-\mathrm{CeO}_{2}$. Following that, the carrier shows stable periodic operation over the duration of the experiment, as indicated by virtually identical carrier weight in the reduced and oxidized states over all cycles and further confirmed in a direct comparison of the rates of weight change during the $1^{\text {st }}$ and $6^{\text {th }}$ oxidation and reduction half cycles shown in figure 6 . Furthermore, the carrier shows high reactivity with a rapid loss/gain of weight in reducing/oxidizing environment. The reduction of $\mathrm{Mn}_{3} \mathrm{O}_{4}$ is restricted to $\mathrm{MnO}$ (confirmed via $\mathrm{XRD}$, not shown here), which can also be deduced from the proximity of the expected and actual sample weight in the post-reduction purge phase. We speculate that the slight additional loss of weight can be explained by some reduction of ceria, as observed in our previous experiments ${ }^{25,33}$. Re-oxidation is rapid and is limited to the $\mathrm{Mn}_{3} \mathrm{O}_{4}$ oxidation state at this temperature which is in agreement with thermodynamic predictions. Thus,

$312 \mathrm{Mn}-\mathrm{CeO}_{2}$ shuttles between $\mathrm{Mn}_{3} \mathrm{O}_{4} \Leftrightarrow \mathrm{MnO}$ during redox cycling with hydrogen/air at $900^{\circ} \mathrm{C}$.

313 Compared to manganese, the contribution of ceria to the oxygen carrying capacity is limited, but 314 the use of ceria as support allows for stable operation of supported manganese carriers. 
315 Moreover, the stable weight of oxygen carrier in the purge phase preceding reduction indicates

316 that $\mathrm{Mn}_{3} \mathrm{O}_{4}$ decomposition does not occur at $900^{\circ} \mathrm{C}$, thus eliminating any complexity due to

317 CLOU-related activity in our experiments. Similarly, other $\mathrm{Mn}_{\mathrm{x}} \mathrm{Fe}_{1-\mathrm{x}}-\mathrm{CeO}_{2}$ carriers that were

318 tested for 5 - 10 cycles in CLC under the same operating conditions and showed similar stable

319 operation (not shown here).

320 Compared to $\mathrm{Mn}-\mathrm{CeO}_{2}$, the redox cycling of the mixed oxides is more interesting to explore due

321 to presence of the bimetallic $\mathrm{FeMnO}_{3}$ phase. This is illustrated here again using the equimolar

322 bimetallic carrier: The last redox cycle in cyclic operation of $\mathrm{Mn}_{0.5} \mathrm{Fe}_{0.5}-\mathrm{CeO}_{2}$ is shown in figure

3237 , where dotted lines again represent the expected sample weights in various oxidation states of

324 the carrier. The materials characterization (section 3.1) had shown that $\mathrm{Mn}_{0.5} \mathrm{Fe}_{0.5}-\mathrm{CeO}_{2}$ is

325 formed upon calcination at $900^{\circ} \mathrm{C}$ (figure $2 \mathrm{~d}$ ). However, similar to the monometallic $\mathrm{Mn}$ carrier,

326 the bimetallic carrier shows thermal decomposition to the lower $\mathrm{Fe}_{3} \mathrm{Mn}_{3} \mathrm{O}_{8}$ oxidation state during

327 the initial heating phase, and the subsequent redox cycles do not exceed this oxidation state.

328 Reduction of the $\mathrm{Mn}_{0.5} \mathrm{Fe}_{0.5}-\mathrm{CeO}_{2}$ from the $\mathrm{Fe}_{3} \mathrm{Mn}_{3} \mathrm{O}_{8}$ oxidation state is two-staged. In the initial 329 stage, exposure to hydrogen results in very rapid reduction in weight, and the subsequent slower 330 reduction stage is preceded by a distinct break in the reduction profile. The carrier weight 331 corresponding to this break is in close agreement with reduction of the carrier to a physical 332 mixture (i.e. de-alloyed phase) of $\mathrm{FeO}$ and $\mathrm{MnO}$ or possibly an alloy of the kind $(\mathrm{Mn}, \mathrm{Fe}) \mathrm{O}$. 333 Furthermore, the sample weight during the post-reduction purge correlates well with a mix of $334(\mathrm{MnO}+\mathrm{Fe})-\mathrm{CeO}_{2}$, which was further confirmed via XRD (figure 8a). Thus, the bimetallic carrier 335 undergoes de-alloying during the reduction process and phase-segregated iron oxide is reduced 336 all the way to metallic Fe, while the reduction of manganese oxide is still restricted to $\mathrm{MnO}$ in 337 the presence of iron. 
338 Similarly, re-oxidation of the de-alloyed carrier consists of two steps with different rates of 339 oxidation. Once again, the sample weight corresponding to the transition point between the two 340 processes is in good agreement with the break observed in the reduction profile and thus with a $341(\mathrm{FeO}+\mathrm{MnO})$ phase. Remarkably, upon re-oxidation, the metals undergo re-alloying, re-forming 342 the initial $\mathrm{Fe}_{3} \mathrm{Mn}_{3} \mathrm{O}_{8}$ phase as confirmed in XRD (figure 8b). Absence of any $\mathrm{Fe}_{2} \mathrm{O}_{3}$ peaks in the 343 X-ray diffraction pattern suggests that the phase-segregated iron is completely incorporated into 344 the manganese structure. Furthermore, similar to the re-oxidation of manganese, which results in 345 formation of $\mathrm{Mn}_{3} \mathrm{O}_{4}$ (rather than $\mathrm{Mn}_{2} \mathrm{O}_{3}$ ), iron associated with manganese is also restricted to the $346 \mathrm{Fe}^{2+/ 3+}$ oxidation state.

347 Unlike in the equimolar $\mathrm{Mn}_{0.5} \mathrm{Fe}_{0.5}-\mathrm{CeO}_{2}$ carrier, the more iron-enriched $\mathrm{Mn}_{0.33} \mathrm{Fe}_{0.67}-\mathrm{CeO}_{2}$ 348 carrier shows the presence of free iron which undergoes full oxidation to $\mathrm{Fe}_{2} \mathrm{O}_{3}$, resulting in a 349 mix of $\mathrm{Fe}_{3} \mathrm{Mn}_{3} \mathrm{O}_{8}$ and $\mathrm{Fe}_{2} \mathrm{O}_{3}$ (not shown here).

350 Thus, these $\mathrm{Mn}_{\mathrm{x}} \mathrm{Fe}_{1-\mathrm{x}}-\mathrm{CeO}_{2}$ carriers exhibit an unusual de-alloying and re-alloying behavior, 351 schematically summarized in figure 8c. Although use of ceria stabilizes supported manganese by 352 avoiding the formation of a spinel phase, it cannot alter the thermodynamics of iron and 353 manganese oxides and maintain the integrity of the bimetallic phase during redox operation. 354 Such atypical large-scale migration of metals when exposed to redox environment has been 355 reported before, where reduction of the bixbyite phase resulted in formation of a $(\mathrm{Mn}, \mathrm{Fe}) \mathrm{O}$ alloy 356 phase which subsequently bleed metallic iron ${ }^{32}$. Table 1 summarizes the various iron and 357 manganese phases detected by XRD at different stages of redox cycling, i.e. post-calcination, 358 post-reduction and post-reoxidation, for all the carriers in the present study. 
359 For very Fe-rich carriers, calcined $\mathrm{Mn}_{0.1} \mathrm{Fe}_{0.9}-\mathrm{CeO}_{2}$ only shows the presence of $\mathrm{Fe}_{2} \mathrm{O}_{3}$ and no 360 separate Mn-oxide diffractions are observed in XRD (figure 2f). These carriers were also 361 subjected to redox cycling in $\mathrm{H}_{2}-\mathrm{TGA}$, and XRD of the reduced sample confirms the presence of 362 metallic Fe along-with weak reflections of $\mathrm{MnO}$ (Table 1). Thus, the sample shows some signs 363 of de-alloying, and after subsequent re-oxidation of the carrier only $\mathrm{Fe}_{2} \mathrm{O}_{3}$ could be detected. In 364 combination with the material balance in TGA, this observation suggests that for very Fe-rich 365 carriers, Mn is able to freely bleed in-and-out of the Fe-oxide structure depending on the 366 reducing or oxidizing environment.

367 Finally, on the other end of the composition spectrum, Mn-rich carriers $\left(\mathrm{Mn}_{0.9} \mathrm{Fe}_{0.1}-\mathrm{CeO}_{2}\right.$ and $368 \mathrm{Mn}_{0.8} \mathrm{Fe}_{0.2}-\mathrm{CeO}_{2}$ ) show the presence of only $\mathrm{Mn}_{2} \mathrm{O}_{3}$ after calcination. Surprisingly, carriers 369 removed from redox cycling in the reduced state confirm formation of $\mathrm{MnO}$ with minor traces of 370 metallic iron in XRD (Table 1). This suggests that most of the iron is still dispersed in the MnO 371 structure, i.e. that the Mn-rich carriers do not undergo phase separation. Re-oxidation of the 372 carriers forms $\mathrm{Mn}_{3} \mathrm{O}_{4}$ and shows no signs of a free iron oxide phase.

373 For a direct comparison of the behavior of all carriers in these $\mathrm{H}_{2}$ /air redox cycles, figure $9 \mathrm{a}$ 374 summarizes the oxygen carrier utilization and reduction kinetics as a function of composition 375 [i.e. Fe-content $\left.=\mathrm{n}_{\mathrm{Fe}} /\left(\mathrm{n}_{\mathrm{Fe}}+\mathrm{n}_{\mathrm{Mn}}\right)\right]$. Here, carrier utilization is defined as the ratio of oxygen 376 consumed to total oxygen contained in the carrier. Thus, for pure iron or manganese carriers, 377 shuttling between $\mathrm{Fe}_{2} \mathrm{O}_{3} \Leftrightarrow \mathrm{Fe}$ and $\mathrm{Mn}_{2} \mathrm{O}_{3} \Leftrightarrow \mathrm{Mn}$, respectively, would result in carrier utilization 378 of 1 . The straight, solid line in figure $9 \mathrm{a}$ represents the carrier utilization obtained for a pure 379 linear superposition of the oxygen carrying capacity of a pure Mn and a pure Fe-based carrier 380 (i.e. for a simple physical mixture of iron and manganese carriers); the line does not take into 381 account any additional oxygen that might be supplied by a reducible support like ceria. Since 
382 manganese only shuttles between $\mathrm{Mn}_{3} \mathrm{O}_{4} \Leftrightarrow \mathrm{MnO}$ and thus only partially utilizes the 383 theoretically available lattice oxygen, it results in a rather low carrier utilization of 0.22 , as 384 indicated by this line for $\mathrm{Fe}=0 \%$. For pure $\mathrm{Fe}$, carrier utilization is 1 , since iron can undergo 385 complete redox cycling between $\mathrm{Fe}_{2} \mathrm{O}_{3} \Leftrightarrow$ Fe. Hence, going across from pure Mn to pure Fe, the 386 carrier utilization represented by the line increases monotonously with increasing iron content.

387 In the same graph, the rate of reduction is represented by the rate of loss of oxygen $\left(\mathrm{dn}_{\mathrm{o}} / \mathrm{dt}\right)_{\mathrm{avg}}(\mathrm{in}$ 388 moles, averaged over the range of $0-80 \%$ of relative carrier utilization), normalized by weight 389 of the oxygen carrier $\left[\mathrm{W}_{\mathrm{ox}}\right]$ in the oxidized state. Since the rate of oxygen loss slows down 390 substantially towards the end of the reduction half-cycle due to exhaustion of active material, the 391 rate of loss of oxygen was averaged only over the range of $0-80 \%$ oxygen consumption.

392 From figure 9a, it can be seen that carrier utilization obtained during redox cycling of $\mathrm{Mn}^{-\mathrm{CeO}_{2}}$ 393 is in agreement with a cycling between $\mathrm{Mn}_{3} \mathrm{O}_{4} \Leftrightarrow \mathrm{MnO}$. Similarly, as expected, Fe-CeO ${ }_{2}$ shows 394 complete carrier utilization. The slight increase in the carrier utilization compared to the 395 expected theoretical values can again be attributed to a small contribution from reduction of the 396 ceria support, as reported before ${ }^{25,33}$. For all bimetallic $\mathrm{Mn}_{\mathrm{x}} \mathrm{Fe}_{1-\mathrm{x}}-\mathrm{CeO}_{2}$ carriers, the carrier 397 utilization is in close agreement with the values predicted from a linear superposition of the pure 398 components. This makes sense in view of the above discussed evidence for de-alloying of iron 399 and manganese during the reduction half cycle in TGA, which results in the formation of free $400 \mathrm{MnO}$ and $\mathrm{Fe}$ (see also table 1). Although the two phases re-alloy during subsequent re-oxidation, 401 such large-scale de-alloying eliminates the possibility of synergistic effects by combining iron 402 and manganese with the aim of altering the thermodynamic properties of the resulting carriers. 
403 While pure manganese has a lower effective oxygen carrying capacity than iron, the rate data in 404 figure 9a shows that it has a significantly higher rate of reduction. Additionally, doping small 405 quantities of iron into manganese further increases the rate of oxygen consumption. As discussed 406 above, iron is completely dissolved into the $\mathrm{Mn}_{2} \mathrm{O}_{3}$ structure in these carriers and these results 407 hence suggest that the presence of this dopant might change the oxygen activity in this oxide, 408 making it more facile to react with the fuel.

409 In contrast to that, carriers with $\mathrm{FeMnO}_{3}$ as the major phase show reduced rates of oxygen loss. 410 This can be understood by the de-alloying of the carriers, as the drastic drop in reduction kinetics 411 concurs with the occurrence of $\mathrm{FeO}+\mathrm{MnO}$ (or a mixed phase of $(\mathrm{Mn}, \mathrm{Fe}) \mathrm{O}$; see figure 7), and 412 subsequent reduction is quite slow (and slower than that of pure iron oxide). This agrees with a 413 previous report that reduction of $(\mathrm{Mn}, \mathrm{Fe}) \mathrm{O}$ is slow and consists of gradual bleed-out of iron 414 atoms which form large iron particles, which were large enough to be detected by $\mathrm{XRD}^{32}$. Thus 415 the strong drop in the average reduction rate can be attributed to the large-scale migration of 416 iron, i.e. the solid state diffusion of Fe is becoming the slow, rate-limiting step in the reduction. 417 On the other end of the composition spectrum, for Fe-rich carriers, doping of manganese shows 418 only marginal effects.

419 Overall, the cyclic TGA tests with hydrogen as fuel show that in-situ de-alloying of iron and 420 manganese hampers any possible synergy between the two metals in these carriers. On the 421 contrary, the large-scale migration of iron results in slowed reduction rates. Surprisingly, doping 422 manganese with iron results in accelerated redox kinetics. As a next step, we look to validate 423 these results by employing methane as fuel for CLC tests in TGA. Using this more realistic fuel, 424 the aim is to investigate carrier resistance against coking, selectivity of the fuel oxidation for 
425 combustion products, and potential differences in redox performance as a function of carrier 426 composition.

\subsubsection{Reactivity Tests with $\mathrm{CH}_{4}$ as Fuel:}

429

430

431

432

433

434

435

436

437

438

439

440

441

442 linear superposition line".

443 Independent of the type of fuel used, $\mathrm{Mn}-\mathrm{CeO}_{2}$ shows a higher rate of reduction compared to Fe-

$444 \mathrm{CeO}_{2}$, confirming the relatively high reactivity of manganese supported on ceria. Due to the de445 alloying of the $\mathrm{FeMnO}_{3}$ containing carriers, the average rate of reduction decreases again for 446 these carriers with respect to both monometallic carriers-which can again be attributed to the 
447 slow phase separation/reduction of $(\mathrm{Mn}, \mathrm{Fe}) \mathrm{O}$ oxide-and the slight differences in trends 448 between the curves for $\mathrm{H}_{2}$ and $\mathrm{CH}_{4}$ as fuel are likely due to the differences in reactivity of the 449 carriers with these two fuels.

450 Similarly, for Mn-rich carriers, we see again an increase in the rate of reduction with $\mathrm{CH}_{4}$ similar 451 to that observed with $\mathrm{H}_{2}$ as fuel. Since we do not observe a distinct phase of metallic Fe, most of 452 the iron is likely still in the Mn-oxide structure during the redox cycle, and thus accelerates the 453 oxygen release. Interestingly, unlike in the TGA tests with $\mathrm{H}_{2}, \mathrm{Mn}-\mathrm{CeO}_{2}$ and $\mathrm{Mn}$-rich carriers 454 show a clear increase in the oxygen carrying capacity when redox cycles are fueled with 455 methane. This observation is counter-intuitive, as methane is significantly less reactive than 456 hydrogen. Moreover, the oxygen carrying capacity (or carrier utilization) increases for these Mn457 rich carriers with increasing amount of iron. Interestingly, Mn-rich oxygen carriers were also 458 found to show higher activity and oxygen release capacity in CLOU tests ${ }^{27}$.

459 The unexpected increase in the carrier utilization for these carriers cannot be explained by a 460 deeper reduction of ceria or complete reduction of iron within the manganese structure alone and 461 was hence investigated further. Figure 10a shows a single cycle in detail for a $\mathrm{Mn}_{0.8} \mathrm{Fe}_{0.2}-\mathrm{CeO}_{2}$ 462 carrier using $\mathrm{CH}_{4}$ as fuel at $900^{\circ} \mathrm{C}$. Upon exposure to the reducing environment the sample 463 rapidly loses weight, forming the intermediate $(\mathrm{Mn}, \mathrm{Fe}) \mathrm{O}$ phase or mix of $\mathrm{FeO}$ and $\mathrm{MnO}$. Further 464 reduction to $\mathrm{MnO}$ and $\mathrm{Fe}$ does not show a distinct break in the weight curve, and the carrier loses 465 much more weight than estimated (with reduction rates significantly higher than those of bulk 466 ceria, the reduction of which is very $\operatorname{slow}^{33}$ ). Moreover, the reduced sample shows no distinct Fe 467 phase (only a single very low intensity peak is observed, see figure 10b), which indicates that 468 iron is still present in the MnO structure. EELS analysis (not shown here) also failed to detect 469 any phase segregated iron particles or islands, with iron found only concomitant with 
470 manganese, supporting the interpretation of the XRD results. Thus, one can hypothesize that

471 during reduction of the $(\mathrm{Mn}, \mathrm{Fe}) \mathrm{O}$ phase, $\mathrm{Fe}^{2+}$ occupying the $\mathrm{Mn}^{2+}$ sites in the fcc structure might

472 be undergoing reduction to form $\mathrm{Fe}^{0}$ centers. Formation of such species would create vacancies

473 in the oxygen lattice of the $\mathrm{MnO}$ structure, possibly making it more facile to reduce. However,

474 we only observe the $\mathrm{MnO}$ phase in XRD (figure 10b), no metallic manganese phase is detected.

475 Nevertheless, detection of such an unstable phase (e.g. $\mathrm{MnO}_{1-\mathrm{y}}$ ) is difficult as it might undergo 476 oxidation with ambient air during sample transfer from TGA to XRD, and, in the absence of in-

477 situ XRD characterization (which was not available for the present studies) the attribution of the 478 enhanced reducibility to a deeper reduction of the $\mathrm{Mn}$ in the bimetallic phase remains 479 speculative.

480 Overall, the use of $\mathrm{Mn}_{\mathrm{x}} \mathrm{Fe}_{1-\mathrm{x}}-\mathrm{CeO}_{2}$ oxides with a bixbyite or hematite phase do not show any 481 synergistic effect due to the de-alloying of the carriers during the reduction half cycle. On the 482 other hand, surprisingly, Mn-rich oxides containing small amounts of iron are found to be much 483 more reactive than pure manganese.

\subsection{Reactive Tests in Fixed-bed Reactor:}

486 While TGA tests provide important insights into carrier reactivity, oxygen carrying capacity and 487 stability of the oxygen carrier materials, the flow configuration (and hence gas-solid contacting 488 pattern) in a TGA is not representative for the conditions in fixed-bed or fluidized bed reactors. 489 Therefore, TGA tests cannot yield any insight into fuel conversion or product selectivity in the 490 gas phase. However, selectivity for total combustion of the fuel is a critical parameter in 491 comparing the efficacy of oxygen carrier in the CLC process, as CLC aims to maximize carbon 
492 capture via complete combustion of fuel to $\mathrm{CO}_{2}$ and steam. Side reactions, such as partial 493 oxidation and pyrolysis/cracking of the fuel, are undesired. Thus, as a last step in the present 494 investigation, $\mathrm{Mn}_{\mathrm{x}} \mathrm{Fe}_{1-\mathrm{x}}-\mathrm{CeO}_{2}$ carriers were subjected to redox operation in a fixed-bed reactor 495 configuration.

496 In a typical experiment, the oxygen carrier bed was brought to the reaction temperature of $900^{\circ} \mathrm{C}$ 497 under inert gas and then methane (16.7 vol\% in Ar) was flown over the (initially oxidized) 498 carriers. Moisture was condensed from the product stream in a steam trap and the product gases 499 were then analyzed by mass-spectrometry. Reduction was continued until the carriers were fully 500 reduced, easily monitored by a selectivity switch from total to partial oxidation and finally to 501 methane cracking on the reduced metals. The reduction half cycle was terminated once methane 502 cracking was detected in order to avoid formation of excess carbon on the reduced carriers. The 503 reactor was then purged in Ar and the carriers were re-oxidized in a stream of $20 \mathrm{vol} \% \mathrm{O}_{2}$ in $\mathrm{He}$. 504 During the oxidation, evolution of $\mathrm{CO}$ and $\mathrm{CO}_{2}$ was monitored as an indication for carbon burn505 off. Oxygen break-through indicated complete regeneration of the carriers.

506 Results from these periodic fixed-bed experiments are not shown in detail here. Instead, figure 50711 summarizes the performance of select $\mathrm{Mn}_{\mathrm{x}} \mathrm{Fe}_{1-\mathrm{x}}-\mathrm{CeO}_{2}$ carriers during the reduction half-cycle 508 with methane in the fixed-bed reactor experiments with regard to the methane conversion rate 509 (figure 11a), $\mathrm{CO}_{2}$ selectivity (figure $11 \mathrm{~b}$ ), and rate of oxygen consumption in the carrier (figure 510 11c) as functions of relative carrier reduction (in percent). For simplicity, the highest oxidation 511 states of the two metals, i.e. $\mathrm{Fe}_{2} \mathrm{O}_{3}$ and $\mathrm{Mn}_{2} \mathrm{O}_{3}$, is used as the fully oxidized reference state of the 512 carrier and the metallic state is used as the reduced reference state. Hence, only the curves for 513 pure $\mathrm{Fe}$ and the Fe-rich $\mathrm{Mn}_{0.1} \mathrm{Fe}_{0.9}$ carriers start at $0 \%$ reduction, i.e. at their fully oxidized states, 514 while more Mn-rich carriers can only be oxidized to the $\mathrm{Mn}_{3} \mathrm{O}_{4} / \mathrm{Fe}_{3} \mathrm{O}_{4}$ states (see our XRD and 
515 TGA results discussed above), resulting in a $11.1 \%$ loss of oxygen carrying capacity (i.e. the

$516 \mathrm{Mn}_{2} \mathrm{O}_{3} \Leftrightarrow \mathrm{Mn}_{3} \mathrm{O}_{4}$ transition) and the carrier reduction hence starts at $11.1 \%$.

517 In the following discussion, we will use this data to i) compare the monometallic Fe- and Mn-

$518 \mathrm{CeO}_{2}$ carriers, then ii) evaluate the impact of $\mathrm{Mn}$ on Fe-based carriers by comparing 519 monometallic iron and the $\mathrm{Mn}_{0.1} \mathrm{Fe}_{0.9}-\mathrm{CeO}_{2}$ carrier, iii) evaluate the impact of $\mathrm{Fe}$ on $\mathrm{Mn}$-carriers 520 by comparing monometallic manganese and the $\mathrm{Mn}_{0.8} \mathrm{Fe}_{0.2}-\mathrm{CeO}_{2}$ carrier, and finally iv) to 521 compare the performance of the bixbyite phase $\left(\mathrm{Mn}_{0.5} \mathrm{Fe}_{0.5}-\mathrm{CeO}_{2}\right)$ with pure $\mathrm{Mn}-\mathrm{CeO}_{2}$.

522 For pure $\mathrm{Mn}-\mathrm{CeO}_{2}$, the initial reduction of the carrier from $\mathrm{Mn}_{3} \mathrm{O}_{4}$ to $\mathrm{MnO}$ is highly selective for 523 total oxidation (see figure 11b) and, in agreement with the high stoichiometric demand for 524 oxygen for this reaction path, also shows a relatively high rate of oxygen consumption from the 525 carrier compared to further reduction of the carrier (see figure 11c). Under the reducing 526 environment of methane, reduction of Mn-oxide below $\mathrm{MnO}$ is observed, which can be seen 527 from figure 11 where the conversion, selectivity, and yield traces extend to carrier reductions 528 well beyond $33.3 \%$ (which corresponds to $\mathrm{MnO}$ ). Both the observations are in good agreement 529 with TGA studies. In comparison to the monometallic $\mathrm{Fe}-\mathrm{CeO}_{2}$ carrier, monometallic $\mathrm{Mn}-\mathrm{CeO}_{2}$ 530 shows high $\mathrm{CO}_{2}$ selectivity during reduction of $\mathrm{Mn}_{3} \mathrm{O}_{4}$ to $\mathrm{MnO}$ (equivalent to $\sim 22 \%$ of oxygen 531 consumption), while $\mathrm{Fe}-\mathrm{CeO}_{2}$ is only selective towards total oxidation od methane during 532 reduction from $\mathrm{Fe}_{2} \mathrm{O}_{3}$ to $\mathrm{Fe}_{3} \mathrm{O}_{4}$ (i.e. for $\sim 11 \%$ of the available oxygen), i.e. $\mathrm{Mn}-\mathrm{CeO}_{2}$ not only 533 shows higher carrier reactivity, but it also doubles the usable fraction of the oxygen carrier in 534 comparison to $\mathrm{Fe}-\mathrm{CeO}_{2}$.

535 Comparing monometallic Fe- and bimetallic $\mathrm{Mn}_{0.1} \mathrm{Fe}_{0.9}-\mathrm{CeO}_{2}$ carriers, it can be seen that adding 536 small amounts of manganese into iron does not significantly affect the carrier reactivity. Both the 
rates of fuel conversion and of oxygen loss from the carrier show a marginal improvement for $\mathrm{Mn}_{0.1} \mathrm{Fe}_{0.9}-\mathrm{CeO}_{2}$. Similarly, the highly selective range for total oxidation remains at $\sim 0-11 \%$ of carrier reduction, i.e. the transition from $\mathrm{Fe}_{2} \mathrm{O}_{3}$ to $\mathrm{Fe}_{3} \mathrm{O}_{4}$, and is not affected by the addition of Mn. The Fe-rich carriers hence do not show any benefit of Mn addition for total oxidation of methane, which is the focus of the present report, albeit improved fuel consumption and reduced $\mathrm{CO}_{2}$ selectivity during later stages of the reduction could be promising for partial oxidation of methane via chemical looping ${ }^{51}$.

Increasing the $\mathrm{Mn}$ content to a $\mathrm{Fe}: \mathrm{Mn}=1: 1$ mixture, the bimetallic $\mathrm{Mn}_{0.5} \mathrm{Fe}_{0.5}-\mathrm{CeO}_{2}$ shows reactivity that is strongly different from the Fe-rich carriers and instead closely resembles that of the monometallic $\mathrm{Mn}-\mathrm{CeO}_{2}$. The bixbyite phase shows virtually identical rates of fuel and carrier conversion to the $\mathrm{Mn}$ carrier, and a similar window for high $\mathrm{CO}_{2}$ selectivity. In agreement with the results from the TGA experiments, we again see a slowdown of the reaction kinetics for higher degrees of reduction, where the de-alloying of the $\mathrm{Mn}$ - and Fe- phases appears again to be the rate limiting step. Also as observed in TGA, de-alloying of the carrier during the reduction process allows formation of metallic iron, therefore increasing the overall oxygen carrying capacity of the bixbyite carrier over that of the monometallic Mn carrier (from 70\% to 80\%).

Finally, on the Mn-rich end of the composition spectrum, a strong effect of the addition of Fe into Mn-based carriers can be seen: $\mathrm{Mn}_{0.8} \mathrm{Fe}_{0.2}-\mathrm{CeO}_{2}$ shows a sharp increase in the reactivity of the carriers and a further improvement of the $\mathrm{CO}_{2}$ selectivity to $\sim 100 \%$ during the conversion of $(\mathrm{Mn}, \mathrm{Fe})_{3} \mathrm{O}_{4}$ to $(\mathrm{Mn}, \mathrm{Fe}) \mathrm{O}$, i.e. the window of $\sim 11 \%$ to $\sim 33 \%$ carrier reduction. A similar increase in the carrier reactivity has been previously observed in the context of chemical looping oxygen uncoupling studies conducted in a batch-fluidized bed reactor ${ }^{27-28}$. As discussed in the context of our TGA results above, addition of iron into the manganese structure appears to make the release 
560 of lattice oxygen more facile, and this seems to apply both to thermal decomposition and to 561 chemical reduction. Although the cause of this strong increase in the carrier reactivity is not fully 562 understood at this point, it suggests a very promising direction for further development of 563 manganese-based carriers, as an improved understanding of the root cause for this behavior 564 would allow a rational, targeted engineering of the metal phase (as opposed to an Edisonian trial 565 of a multitude of compositions) and thus yield carriers with improved reactivity for CLC.

566 Overall, both metals chosen in the present investigation ( $\mathrm{Fe}$ and $\mathrm{Mn}$ ) are abundant, 567 environmentally benign, and relatively inexpensive candidates when compared to more reactive 568 metals like nickel and copper. Among the two, as demonstrated in the present work, manganese 569 shows higher reactivity and twice the usable oxygen carrying capacity compared to iron 570 currently considered to be one of the most suitable candidates for CLC. This increased oxygen 571 carrying capacity and carrier reactivity can help reduce the solid inventory of oxygen carrier in 572 looping reactors, a significant consideration in the most often investigated circulating fluidized 573 bed (CFB) configuration for CLC processes. Furthermore, use of $\mathrm{Mn}-\mathrm{CeO}_{2}$ carriers provides an 574 opportunity to improve the heat balance between the exothermic air reactor and the reducer 575 reactor, which is an endothermic stage for virtually all currently investigated CLC carrier 576 materials (with the notable exception of copper, a much more expensive and less 577 environmentally benign metal). The following set of equations $(12-16)$ show the reaction along 578 with the respective heat of reaction at $900^{\circ} \mathrm{C}$ for methane total oxidation and carrier re-oxidation 579 with air (oxygen) for monometallic Fe- and Mn-based systems. It can be seen that use of 580 manganese $\left(\mathrm{Mn}_{3} \mathrm{O}_{4} \Leftrightarrow \mathrm{MnO}\right)$ results in an exothermic carrier reduction reaction, which is not the 581 case for iron $\left(\mathrm{Fe}_{2} \mathrm{O}_{3} \Leftrightarrow \mathrm{Fe}_{3} \mathrm{O}_{4}\right)$, and thus splits the heat load from the total oxidation reaction 582 between the two half cycles. (The net heat of reaction is of course identical for both systems, as 
583 the net reaction yields in all CLC cases the conventional total oxidation of methane.) This is

584 particularly significant for fixed-bed CLC concepts, where heat management constitutes the most

585 critical point in process operation ${ }^{52-53}$. Mn-based carriers thus present an opportunity for more

586 effective use of autothermal fixed-bed reactors in chemical looping combustion, and addition of

587 relatively small amounts of Fe can further improve their operation without significantly affecting

588 the heat balance.

589

$590 \quad \underline{\operatorname{Iron}\left(\mathrm{Fe}_{2}\right.} \underline{\mathrm{O}}_{3} \underline{\mathrm{B}} \Leftrightarrow \mathrm{Fe}_{3} \underline{\mathrm{O}}_{4} \underline{ }_{2}:$

591 Reduction: $12 \mathrm{Fe}_{2} \mathrm{O}_{3}+\mathrm{CH}_{4}=8 \mathrm{Fe}_{3} \mathrm{O}_{4}+\mathrm{CO}_{2}+2 \mathrm{H}_{2} \mathrm{O} \quad \Delta \mathrm{H}_{\mathrm{R}}=+149.2 \mathrm{~kJ} / \mathrm{mol}$

592 Oxidation: $8 \mathrm{Fe}_{3} \mathrm{O}_{4}+2 \mathrm{O}_{2}=12 \mathrm{Fe}_{2} \mathrm{O}_{3} \quad \Delta \mathrm{H}_{\mathrm{R}}=-950.6 \mathrm{~kJ} / \mathrm{mol}$

$593 \quad$ Manganese $\left(\mathrm{Mn}_{3} \underline{O}_{4} \Leftrightarrow \mathrm{MnO}\right)$ :

594 Reduction: $4 \mathrm{Mn}_{3} \mathrm{O}_{4}+\mathrm{CH}_{4}=12 \mathrm{MnO}+\mathrm{CO}_{2}+2 \mathrm{H}_{2} \mathrm{O} \quad \Delta \mathrm{H}_{\mathrm{R}}=-103.0 \mathrm{~kJ} / \mathrm{mol}$

595 Oxidation: $12 \mathrm{MnO}+2 \mathrm{O}_{2}=4 \mathrm{Mn}_{3} \mathrm{O}_{4}$

$\Delta \mathrm{H}_{\mathrm{R}}=-698.4 \mathrm{~kJ} / \mathrm{mol}$

$596 \quad$ Net Reaction of Combustion:

$597 \mathrm{CH}_{4}+2 \mathrm{O}_{2}=\mathrm{CO}_{2}+2 \mathrm{H}_{2} \mathrm{O}$

$\Delta \mathrm{H}_{\mathrm{R}}=-801.4 \mathrm{~kJ} / \mathrm{mol}$

598

599 4. Summary:

600 We presented a comprehensive study of mono- and bimetallic Fe- and $\mathrm{Mn}-\mathrm{CeO}_{2}$ oxygen carriers 601 for chemical looping combustion. The two metals were chosen as they are among the most earth 
602 abundant metals, and are environmentally benign and relatively inexpensive compared to more 603 reactive and widely investigated metals such as $\mathrm{Ni}$ and $\mathrm{Cu}$. While $\mathrm{Fe} / \mathrm{Mn}$-carriers have 604 previously found some attention for CLOU applications ${ }^{27-31,49-50}$, their use for "conventional" 605 chemical looping had to-date not found much attention, and a systematic study of the impact of 606 the formation of mixed metal phases of these two metals was entirely lacking. Extending our 607 previous studies on bimetallic FeNi systems, which had demonstrated the possibility of 608 significant benefits of alloys for CLC in combining the beneficial properties of the two parent 609 metals $^{25}$, the intent of the present study was to identify similar synergistic effects for the FeMn $610 \quad$ system.

611 Mono- and bimetallic Fe and Mn carrier materials were synthesized using a low-cost, scalable 612 technique using ceria as support material. The obtained carriers were evaluated with regard to 613 their bimetallic phase stability, reactivity, oxygen carrying capacity, and cyclic redox stability 614 using $\mathrm{H}_{2}$ and $\mathrm{CH}_{4}$ as fuels in TGA and fixed-bed reactor studies.

615 In agreement with our previous reports ${ }^{25,33}$, the use of ceria as support results in excellent phase 616 stability and stable redox operation of all carriers, which is particularly noteworthy for 617 manganese which has been shown to react with the support matrix of many typical oxygen 618 carrier supports (such as $\mathrm{Al}_{2} \mathrm{O}_{3}$, and many others), forming spinel structures that are inert in 619 further redox cycling. For the two monometallic carriers, both TGA and fixed-bed reactor studies 620 confirm the significantly higher reactivity and oxygen carrying capacity of $\mathrm{Mn}-\mathrm{CeO}_{2}$ vs $\mathrm{Fe}-\mathrm{CeO}_{2}$ $621\left(\mathrm{Fe}_{2} \mathrm{O}_{3} \Leftrightarrow \mathrm{Fe}_{3} \mathrm{O}_{4} ; \sim 11 \%\right.$ vs $\left.\mathrm{Mn}_{3} \mathrm{O}_{4} \Leftrightarrow \mathrm{MnO} ; \sim 22 \%\right)$. Thus, improved kinetics and oxygen 622 carrying capacity coupled with low toxicity and favorable thermodynamics (exothermicity) of 623 the reduction half process make Mn-based oxygen carriers an attractive and pragmatic alternative 624 to iron. 
625 For the bimetallic $\mathrm{Mn}_{\mathrm{x}} \mathrm{Fe}_{1-\mathrm{x}}-\mathrm{CeO}_{2}$ carriers, all carriers show stable redox operation, although 626 carriers with a bixbyite $\mathrm{FeMnO}_{3}$ phase showed large scale migration of iron and manganese 627 resulting in de-alloying of the metal phases. Remarkably, this de-alloying during the reduction 628 process appears to be completely reversible during re-oxidation of the carrier (indicating that the 629 de-alloyed metals must remain in intimate contact). Nevertheless, the de-alloying resulted in an 630 absence of synergistic effects of combining the two metals and in fact adversely affected the 631 carrier reactivity which appears to become rate-limited by the slow solid state diffusion process 632 underlying the de-alloying. Unlike for ceria-supported bimetallic FeNi systems ${ }^{25}$, the persistent 633 de-alloying/re-alloying behavior thus negates the advantage of using ceria as support for $\mathrm{Mn}_{\mathrm{x}} \mathrm{Fe}_{1}$ -

$634 \mathrm{x}^{-} \mathrm{CeO}_{2}$ carriers with high iron content. In contrast to that, for Mn-rich carriers with low iron 635 content $\left(\mathrm{Mn}_{0.8} \mathrm{Fe}_{0.2}-\mathrm{CeO}_{2}\right.$ and $\left.\mathrm{Mn}_{0.9} \mathrm{Fe}_{0.1}-\mathrm{CeO}_{2}\right)$, a strong improvement in the carrier reactivity 636 over $\mathrm{Mn}-\mathrm{CeO}_{2}$ was observed in TGA and fixed-bed studies, which - combined with further 637 enhanced selectivity for total oxidation of the fuel and the advantageous heats of reaction of Mn638 based carriers - makes these carriers of great interest for further investigation in CLC.

639 Overall, our results thus show that combining two relatively low-reactive metals like iron and 640 manganese can indeed yield synergistic effects: Rather than adding a highly reactive secondary 641 metal (like $\mathrm{Ni}$ or $\mathrm{Cu}$ ), the addition of the low-cost, but low-reactivity, Fe not only augments the 642 carrier reactivity at reduced cost, but also mitigates the environmental impact of oxygen carriers. 643 Although our results indicate that these bimetallic oxygen carriers can yield significant 644 improvement over monometallic ones, it is important to gain a better mechanistic understanding 645 of the impact of the secondary metal on the redox performance of oxygen carriers in order to 646 enable a rational tailoring of oxygen carriers. Nevertheless, the present results demonstrate that 647 systematic engineering of the metal phase of oxygen carriers and the use of active, i.e. reducible, 
648 support materials such as ceria can yield high-performance oxygen carriers for chemical looping

649 processes.

650

651 Acknowledgements:

652 This technical effort was performed in support of the U.S. Department of Energy's National

653 Energy Technology Laboratory's on-going research under the RDS contract DE-AC26-

654 04NT41817. Furthermore, financial support by the National Science Foundation (CBET

$655 \quad \# 1159853$ ) and by the University of Pittsburgh's Mascaro Center for Sustainable Innovation is

656 gratefully acknowledged. Finally, we would like to thank Prashant Kumta and Karan Kadakia for

657 their help with Rietveld analysis. 
659 Table 1: Iron and manganese phases detected in $\mathrm{XRD}$ for $\mathrm{Mn}_{\mathrm{x}} \mathrm{Fe}_{1-\mathrm{x}}-\mathrm{CeO}_{2}$ carriers subjected to 660 calcination and redox cycling at $900^{\circ} \mathrm{C}$. Phases in parenthesis are minor phases in the sample 661 with only one or two low-intensity diffraction peaks detectable in the XRD spectrum.

\section{Phases detected in XRD}

Carriers

\begin{tabular}{llll} 
& After calcination & & \\
\cline { 3 - 3 } & & Reduced $\left(\mathrm{H}_{2}\right.$ or $\left.\mathrm{CH}_{4}\right)$ & $\mathrm{Re}$-oxidized (air) \\
$\mathrm{Mn} \mathrm{CeO}_{2}$ & $\mathrm{Mn}_{2} \mathrm{O}_{3}$ & $\mathrm{MnO}$ & $\mathrm{Mn}_{3} \mathrm{O}_{4}$ \\
$\mathrm{Mn}_{0.9} \mathrm{Fe}_{0.1}-\mathrm{CeO}_{2}$ & $\mathrm{Mn}_{2} \mathrm{O}_{3}$ & $\mathrm{MnO},(\mathrm{Fe})$ & $\mathrm{Mn}_{3} \mathrm{O}_{4}$ \\
$\mathrm{Mn}_{0.8} \mathrm{Fe}_{0.2}-\mathrm{CeO}_{2}$ & $\mathrm{Mn}_{2} \mathrm{O}_{3}$ & $\mathrm{MnO},(\mathrm{Fe})$ & $\mathrm{Mn}_{3} \mathrm{O}_{4}$ \\
$\mathrm{Mn}_{0.5} \mathrm{Fe}_{0.5}-\mathrm{CeO}_{2}$ & $\mathrm{FeMnO}_{3}$ & $\mathrm{MnO}, \mathrm{Fe}$ & $\mathrm{Fe}_{3} \mathrm{Mn}_{3} \mathrm{O}_{8}$ \\
$\mathrm{Mn}_{0.33} \mathrm{Fe}_{0.67}-\mathrm{CeO}_{2}$ & $\mathrm{FeMnO}_{3}, \mathrm{Fe}_{2} \mathrm{O}_{3}$ & $\mathrm{MnO}, \mathrm{Fe}$ & \\
$\mathrm{Mn}_{0.1} \mathrm{Fe}_{0.9}-\mathrm{CeO}_{2}$ & $\mathrm{Fe}_{2} \mathrm{O}_{3}$ & & $\mathrm{Fe}_{3} \mathrm{Mn}_{3} \mathrm{O}_{8}, \mathrm{Fe}_{2} \mathrm{O}_{3}$ \\
$\mathrm{Fe}_{-\mathrm{CeO}_{2}}$ & & $\mathrm{MnO}, \mathrm{Fe}$ & $\mathrm{Fe}_{2} \mathrm{O}_{3}$ \\
\hline
\end{tabular}

After redox cycling in TGA at $900^{\circ} \mathrm{C}$ 
663 Figures:

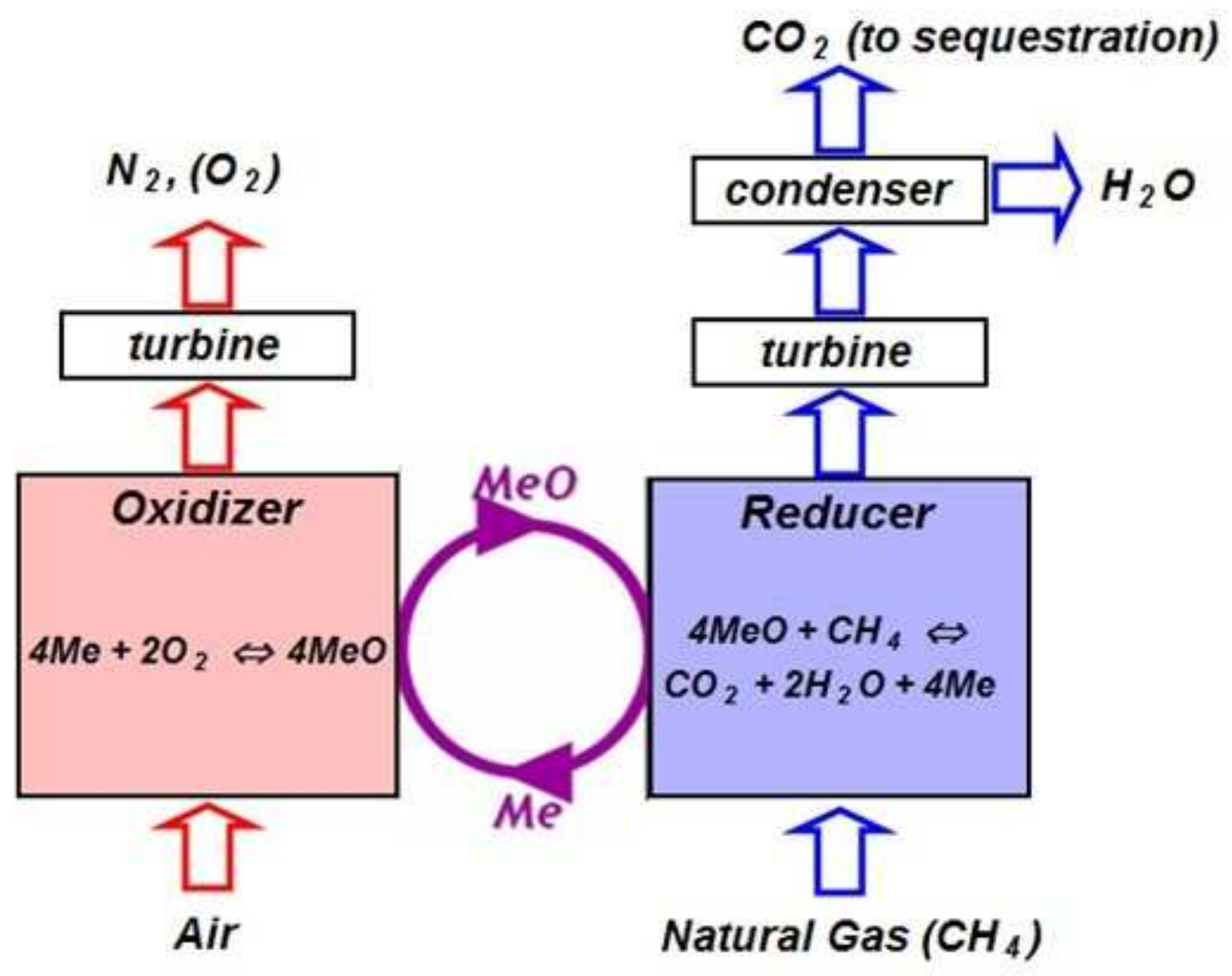

664

665 Figure 1: Schematic for chemical looping combustion using $\mathrm{CH}_{4}$ as fuel. 


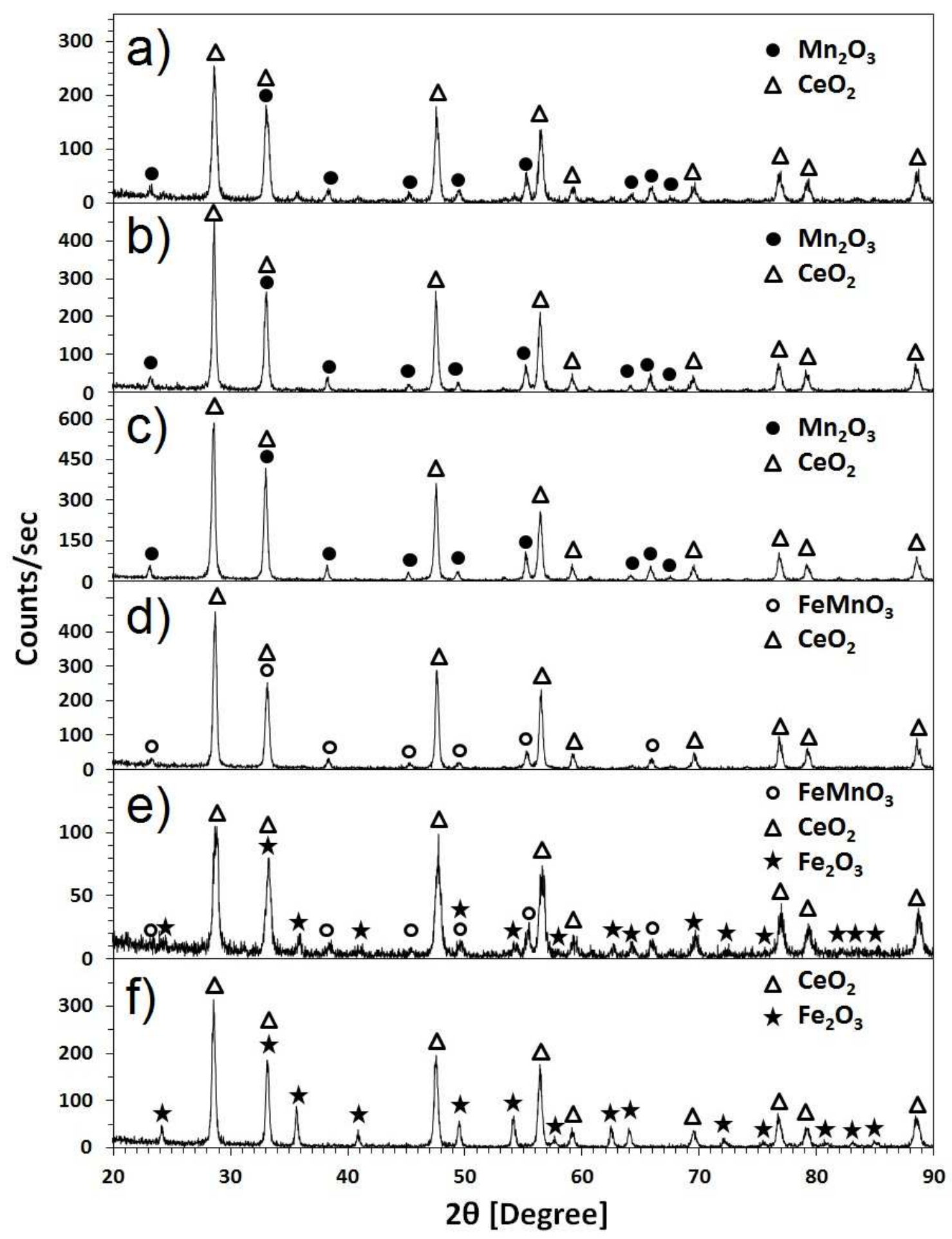

667 Figure 2: Typical X-ray diffraction patterns of $\mathrm{Mn}_{\mathrm{x}} \mathrm{Fe}_{1-\mathrm{x}}-\mathrm{CeO}_{2}$ carriers after calcination at $900^{\circ} \mathrm{C}$ 668 for $2 \mathrm{~h}(0.2 \mathrm{SLM}$ air) where a) $\mathrm{x}=1, \mathrm{~b}) \mathrm{x}=0.9, \mathrm{c}) \mathrm{x}=0.8, \mathrm{~d}) \mathrm{x}=0.5, \mathrm{e}) \mathrm{x}=0.33$ and $\mathrm{f}) \mathrm{x}=0.1$. 


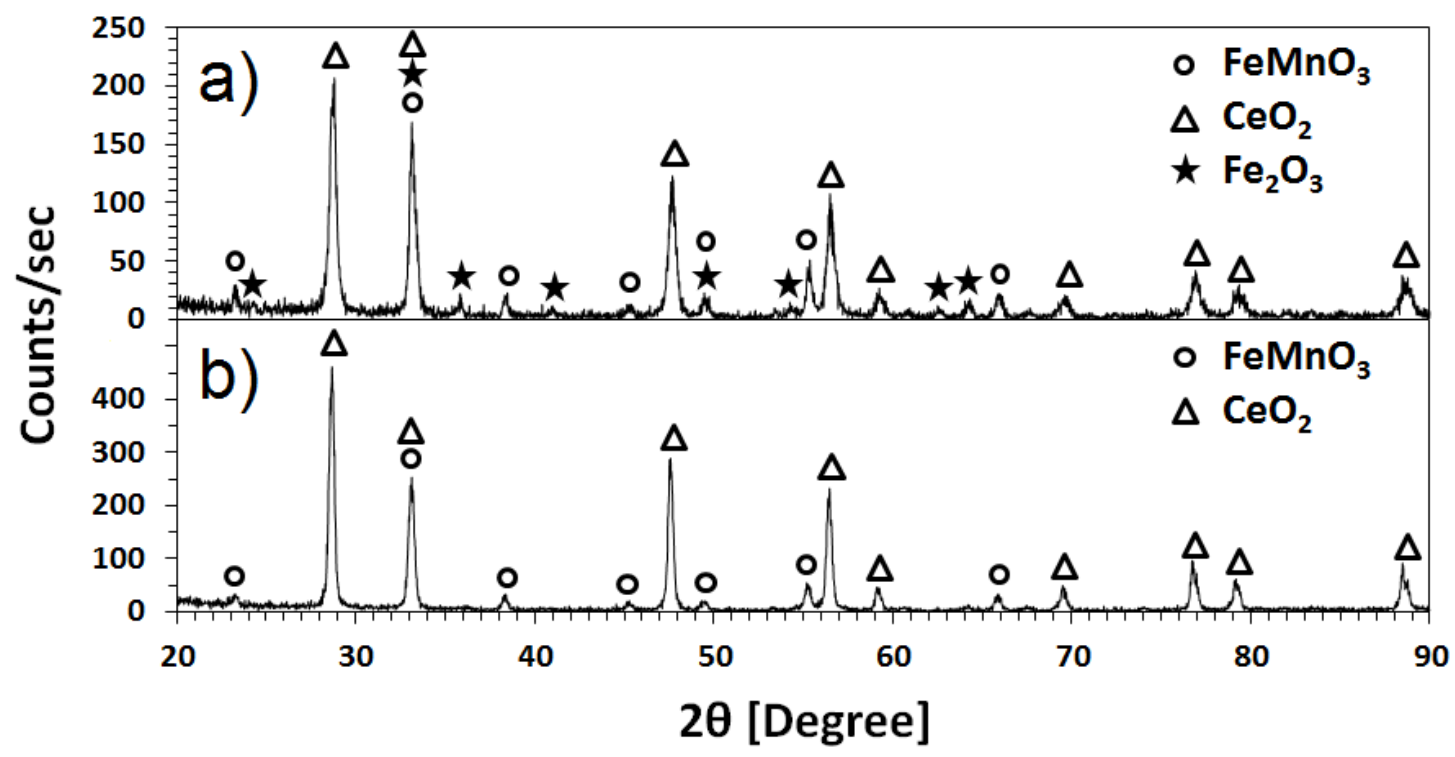

670 Figure 3: $\mathrm{X}$-ray diffraction pattern showing the effect of calcination temperature a) $800^{\circ} \mathrm{C}$ and b) $671900^{\circ} \mathrm{C}$ on $\mathrm{Mn}_{0.5} \mathrm{Fe}_{0.5}-\mathrm{CeO}_{2}$ (calcined in $0.2 \mathrm{SLM}$ air for $2 \mathrm{~h}$ ). Calcination of carriers at $900^{\circ} \mathrm{C}$ 672 leads to loss of free $\mathrm{Fe}_{2} \mathrm{O}_{3}$ phase confirming formation of bimetallic $\mathrm{FeMnO}_{3}$ phase.

673

674

675

676 

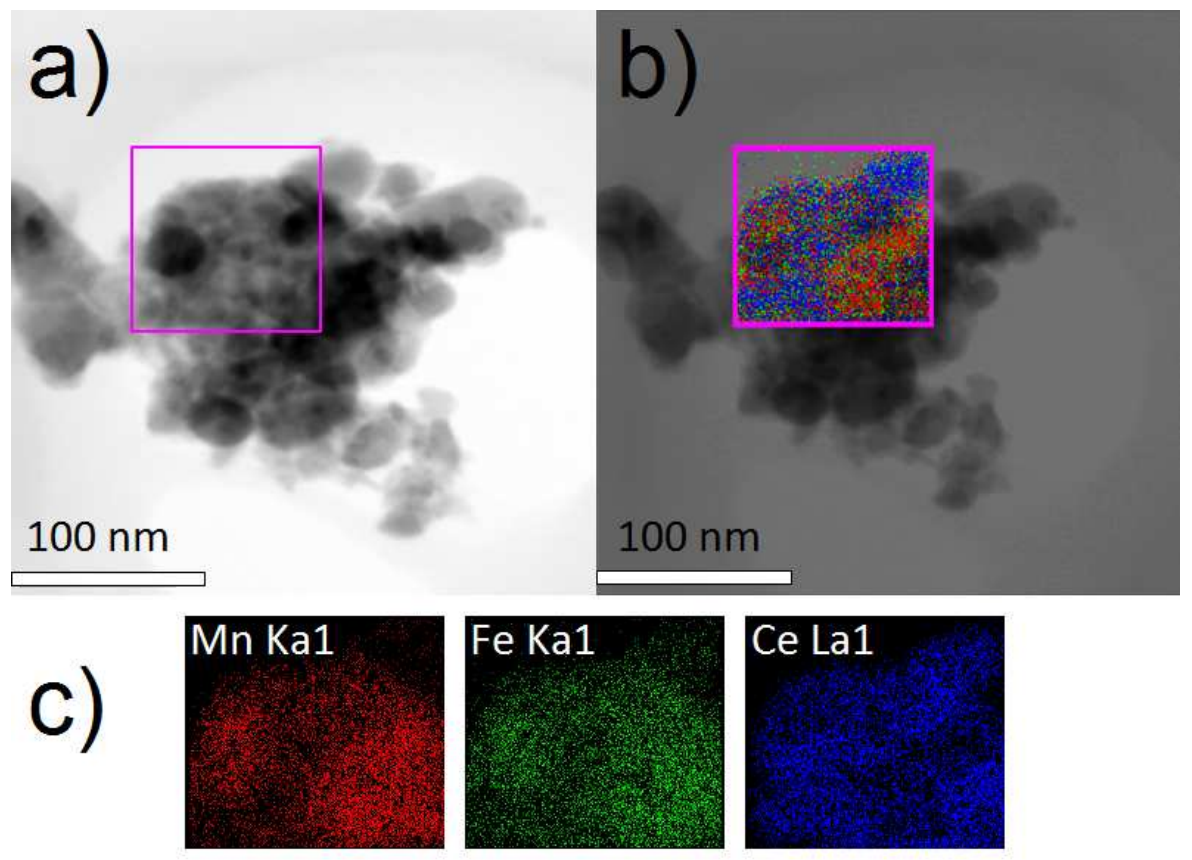

678 Figure 4: TEM image of a $\mathrm{Mn}_{0.5} \mathrm{Fe}_{0.5}-\mathrm{CeO}_{2}$ sample (a) without and (b) with superimposed EELS 679 elemental maps; and c) elemental distribution of individual elements Mn (left), Fe (middle) and $680 \mathrm{Ce}$ (right) after calcination at $900^{\circ} \mathrm{C}$ in $0.2 \mathrm{SLM}$ air for $2 \mathrm{~h}$ (scale of the distribution maps is $\left.681 \sim 100^{*} 100 \mathrm{~nm}\right)$. The EELS analysis confirms occurrence of Fe and $\mathrm{Mn}$ in close vicinity on the 682 nanometer scale. 


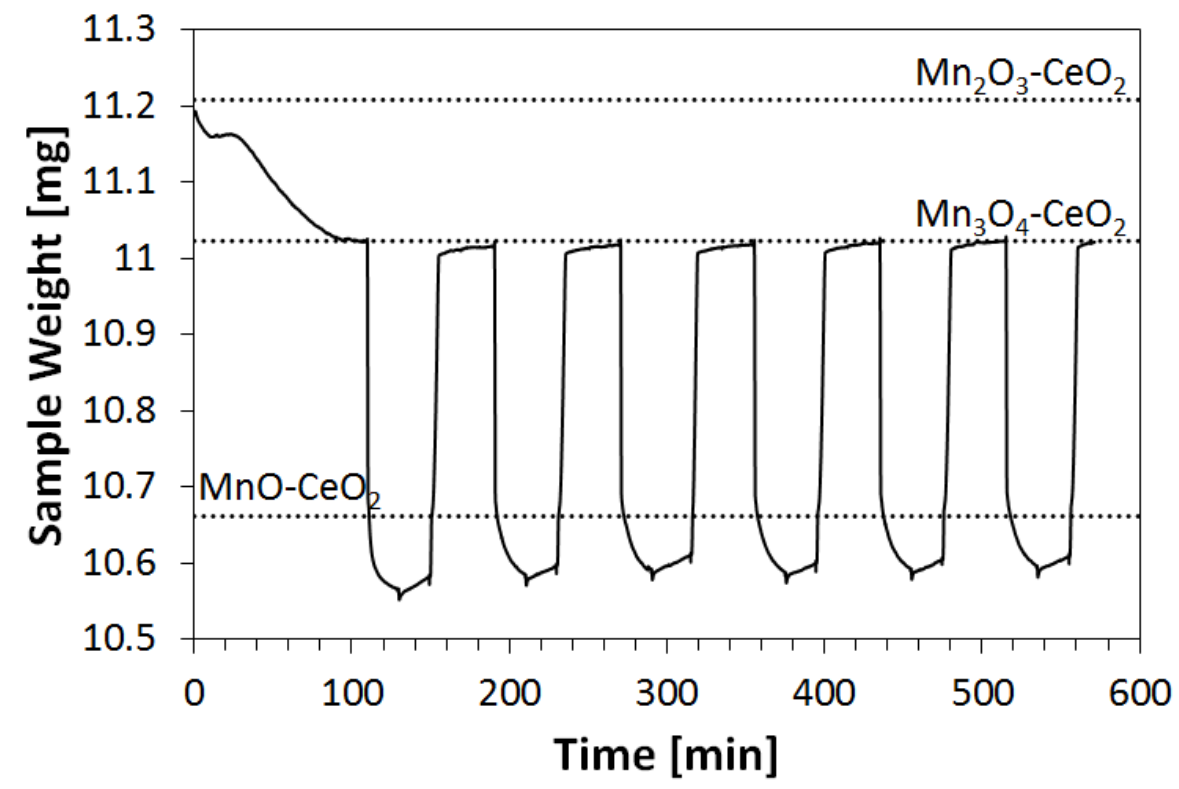

686

687 Figure 5: Stable CLC redox cycles of $\mathrm{Mn}-\mathrm{CeO}_{2}$ in TGA at $900^{\circ} \mathrm{C}$ with reduction in $\mathrm{H}_{2}, \mathrm{~N}_{2}$ 688 purge, and oxidation in air. The dotted lines show the calculated sample weight for various 689 oxidation states of manganese (based on the nominal weight loading of Mn).

690

691 


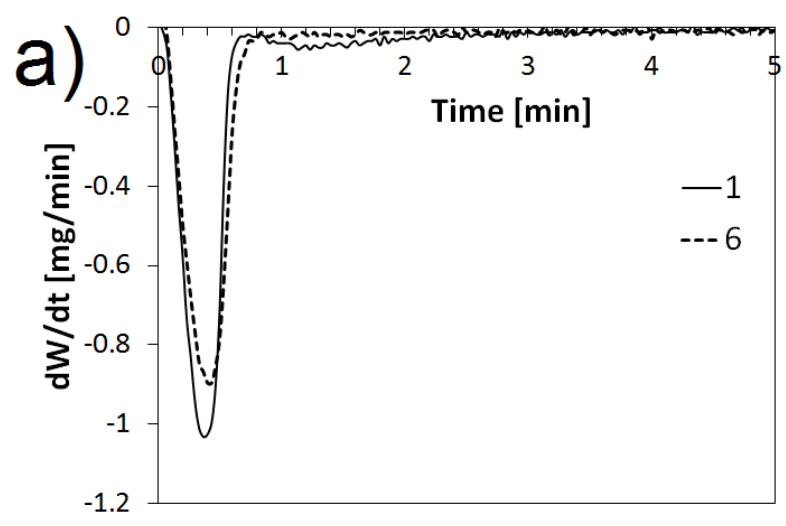

692

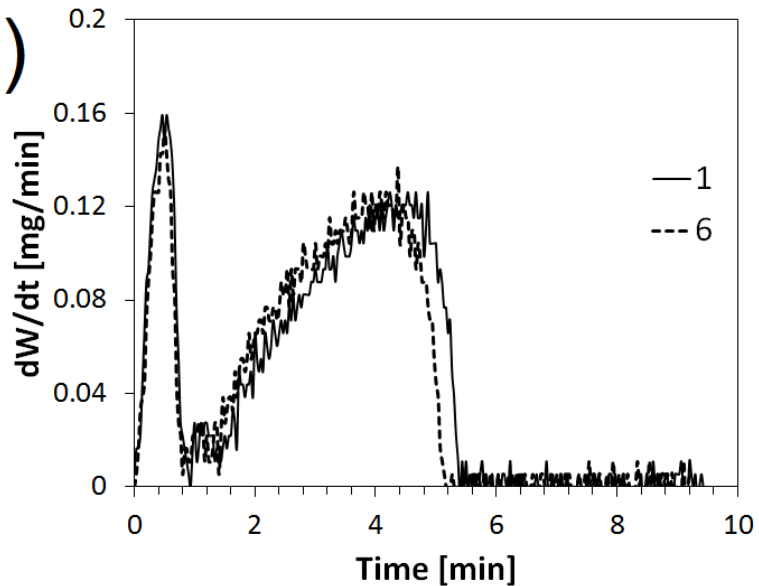

693 Figure 6: Comparison of rate of weight change between first and sixth redox cycle for $\mathrm{Mn}-\mathrm{CeO}_{2}$

694 carriers during a) reduction and b) oxidation half cycles in TGA at $900^{\circ} \mathrm{C}$ using $\mathrm{H}_{2}$ and air 695 respectively.

696

697

698 


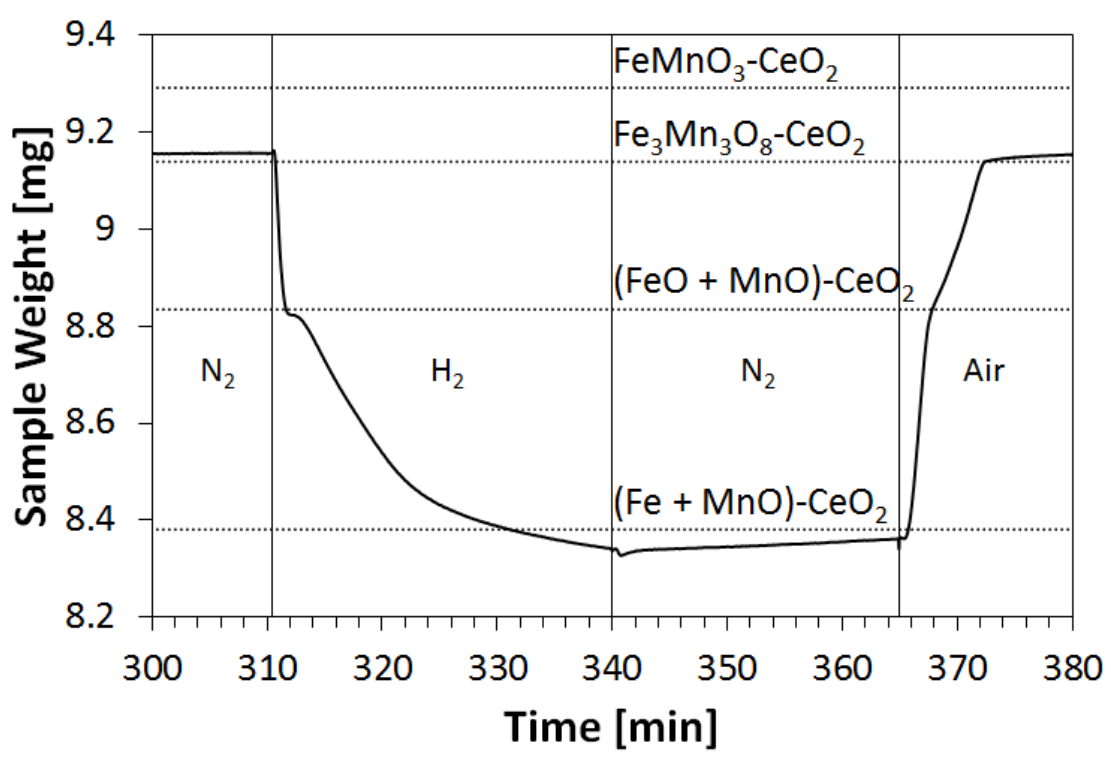

700

701 Figure 7: Single redox cycle of $\mathrm{Mn}_{0.5} \mathrm{Fe}_{0.5}-\mathrm{CeO}_{2}$ in TGA at $900^{\circ} \mathrm{C}$ with reduction in $\mathrm{H}_{2}, \mathrm{~N}_{2}$ 702 purge, and oxidation in air. The dotted lines show the calculated sample weight for various 703 oxidation states of manganese and iron (based on nominal weight loadings of $\mathrm{Fe}$ and $\mathrm{Mn}$ ).

704

705

706

707

708

709

710

711

712

713 


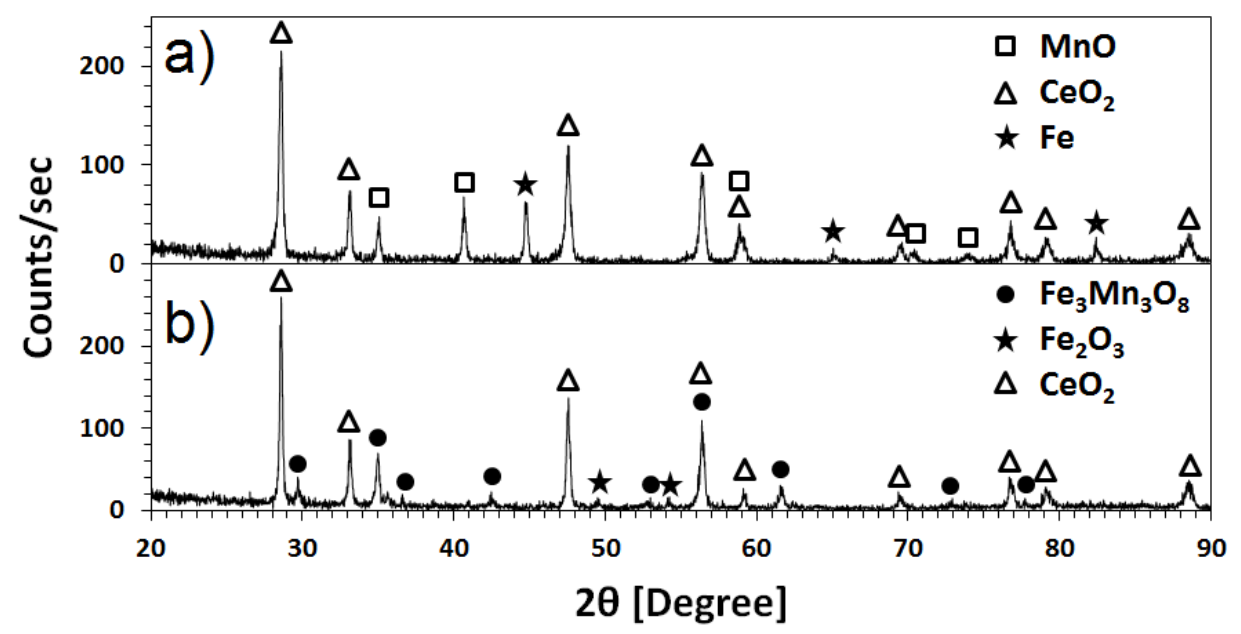

c)

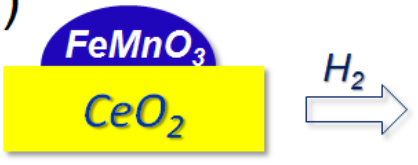

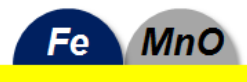

$\mathrm{CeO}_{2-x}$
$\mathrm{Fe}_{3} \mathrm{Mn}_{3} \mathrm{O}_{8}$ $\mathrm{CeO}_{2}$

716 Figure 8: X-ray diffraction pattern of $\mathrm{Mn}_{0.5} \mathrm{Fe}_{0.5}-\mathrm{CeO}_{2}$ after a) reduction in $\mathrm{H}_{2}(20 \mathrm{sccm})$ and b)

717 re-oxidation in air $(20 \mathrm{sccm})$ at $900^{\circ} \mathrm{C}$; c) schematic illustration of the unusual de-alloying and 718 re-alloying of iron and manganese observed during redox cycling of $\mathrm{Mn}_{0.5} \mathrm{Fe}_{0.5}-\mathrm{CeO}_{2}$ in $\mathrm{CLC}$ at $719900^{\circ} \mathrm{C}$.

720

721 

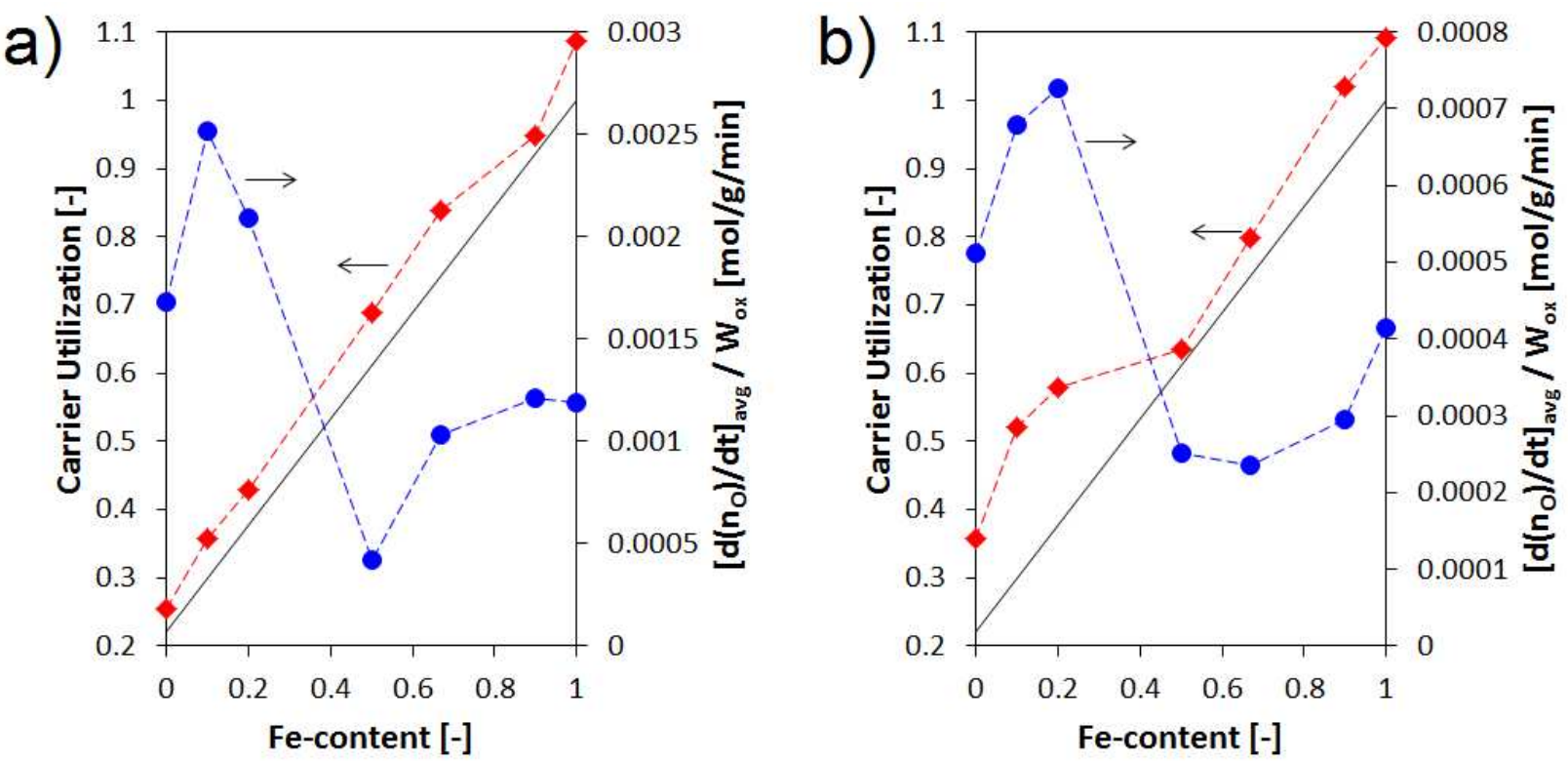

723 Figure 9: Carrier utilization and rate of oxygen loss $\left(\mathrm{d}\left(\mathrm{n}_{\mathrm{o}}\right) / \mathrm{dt}\right.$, avg; averaged over $0-80 \%$ oxygen 724 utilization and normalized by the weight of the oxidized carrier, $\mathrm{W}_{\mathrm{ox}}$ ) for $\mathrm{Mn}_{\mathrm{x}} \mathrm{Fe}_{1-\mathrm{x}}-\mathrm{CeO}_{2}$ carriers 725 as a function of Fe-content in TGA redox cycles at $900^{\circ} \mathrm{C}$ using a) $\mathrm{H}_{2}$ and b) $\mathrm{CH}_{4}$ as fuel. The 726 gray solid line corresponds to the calculated carrier utilization for a linear superposition of the 727 monometallic carriers (i.e. a physical mixture of Fe- and Mn-oxides). 

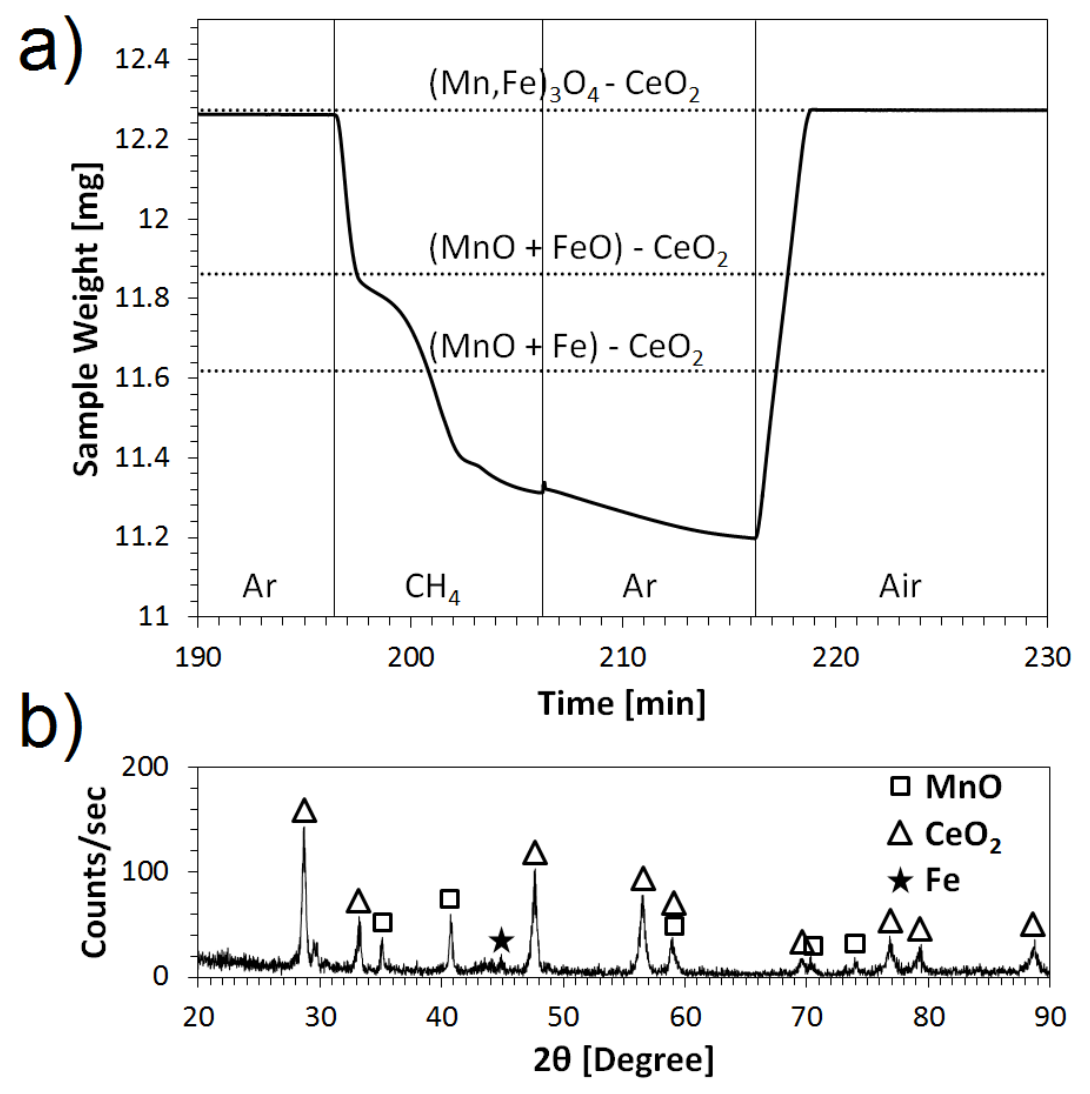

729 Figure 10: a) Single redox cycle of $\mathrm{Mn}_{0.8} \mathrm{Fe}_{0.2}-\mathrm{CeO}_{2}$ in $\mathrm{TGA}$ at $900^{\circ} \mathrm{C}$ using $\mathrm{CH}_{4}$ as fuel (5 $730 \mathrm{sccm})$, argon purge $(20 \mathrm{sccm})$ and air oxidation $(20 \mathrm{sccm})$; b) XRD of $\mathrm{Mn}_{0.8} \mathrm{Fe}_{0.2}-\mathrm{CeO}_{2}$ carrier 731 after reduction in TGA using $\mathrm{CH}_{4}$ at $900^{\circ} \mathrm{C}$. 

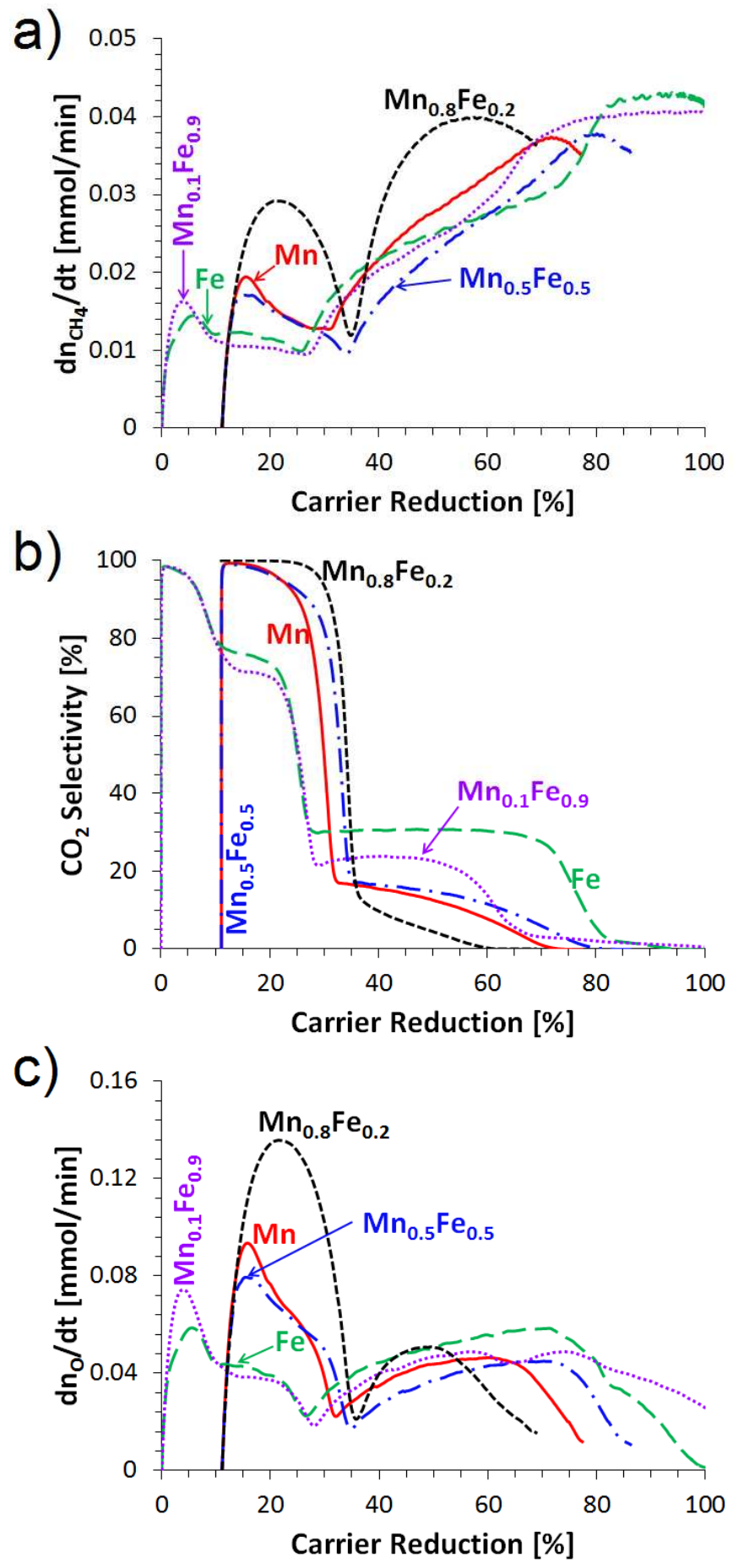

733 Figure 11: Comparison of select $\mathrm{Mn}_{\mathrm{x}} \mathrm{Fe}_{1-\mathrm{x}}-\mathrm{CeO}_{2}$ carriers ( $\mathrm{x}=0$ : solid line; 0.1: dotted line; 0.5: 734 dot-dashed line; 0.8: short-dashed line; 1: long-dashed line) during reduction with methane (16.7 735 vol.\%, $1 \mathrm{sccm}$ ) in fixed-bed reactor experiments at $900^{\circ} \mathrm{C}$ : a) rate of methane conversion, b) $\mathrm{CO}_{2}$ 736 selectivity and c) rate of oxygen consumption vs relative carrier reduction (in percent). 


\section{References:}

738 (1) Adanez, J.; Abad, A.; Garcia-Labiano, F.; Gayan, P.; de Diego, L. F. Progress in Chemical-Looping Combustion and Reforming technologies. Prog. Energy Combust. Sci. 2012, 38, 215-282.

(2) Moghtaderi, B. Review of the Recent Chemical Looping Process Developments for Novel Energy and Fuel Applications. Energy \& Fuels 2012, 26, 15-40.

(3) Hossain, M. M.; de Lasa, H. I. Chemical-looping combustion (CLC) for inherent CO2 separations-a review. Chem. Eng. Sci. 2008, 63, 4433-4451.

(4) Anheden, M.; Svedberg, G. Exergy analysis of chemical-looping combustion systems. Energy Conv. Manag. 1998, 39, 1967-1980.

746

747

748

749

750

751

752

753

(5) Kvamsdal, H. M.; Jordal, K.; Bolland, O. A quantitative comparison of gas turbine cycles with $\mathrm{CO}(2)$ capture. Energy 2007, 32, 10-24.

(6) Naqvi, R.; Wolf, J.; Bolland, O. Part-load analysis of a chemical looping combustion (CLC) combined cycle with CO2 capture. Energy 2007, 32, 360-370.

(7) Wolf, J.; Anheden, M.; Yan, J. Y. Comparison of nickel- and iron-based oxygen carriers in chemical looping combustion for $\mathrm{CO} 2$ capture in power generation. Fuel 2005, 84, 993-1006.

(8) Adanez, J.; Gayan, P.; Celaya, J.; de Diego, L. F.; Garcia-Labiano, F.; Abad, A. Chemical looping combustion in a $10 \mathrm{~kW}($ th) prototype using a CuO/Al2O3 oxygen carrier: Effect of operating conditions on methane combustion. Industrial \& Engineering Chemistry Research 2006, 45, 6075-6080.

754

755

756

757

758

759

760

761

762

763

764

765

766

767

768

769

770

771

772

773

774

775

776

777

778

(9) Linderholm, C.; Mattisson, T.; Lyngfelt, A. Long-term integrity testing of spray-dried particles in a 10-kW chemical-looping combustor using natural gas as fuel. Fuel 2009, 88, 2083-2096.

(10) Lyngfelt, A. Oxygen Carriers for Chemical Looping Combustion - $4000 \mathrm{~h}$ of Operational Experience. Oil \& gas science and technology 2011, 66, 161-172.

(11) Pröll, T.; Mayer, K.; Bolhàr-Nordenkampf, J.; Kolbitsch, P.; Mattisson, T.; Lyngfelt, A.; Hofbauer, $\mathrm{H}$. Natural minerals as oxygen carriers for chemical looping combustion in a dual circulating fluidized bed system. Energy Procedia 2009, 1, 27-34.

(12) Rifflart, S.; Hoteit, A.; Yazdanpanah, M. M.; Pelletant, W.; Surla, K. Construction and operation of a $10 \mathrm{~kW}$ CLC unit with circulation configuration enabling independent solid flow control. Energy Procedia 2011, 4, 333-340.

(13) Shen, L. H.; Wu, J. H.; Xiao, J.; Song, Q. L.; Xiao, R. Chemical-Looping Combustion of Biomass in a $10 \mathrm{~kW}$ (th) Reactor with Iron Oxide As an Oxygen Carrier. Energy \& Fuels 2009, 23, 2498-2505.

(14) Cho, P.; Mattisson, T.; Lyngfelt, A. Comparison of iron-, nickel-, copper- and manganese-based oxygen carriers for chemical-looping combustion. Fuel 2004, 83, 1215-1225.

(15) Garcia-Labiano, F.; Adanez, J.; de Diego, L. F.; Gayan, P.; Abad, A. Effect of pressure on the behavior of copper-, iron-, and nickel-based oxygen carriers for chemical-looping combustion. Energy \& Fuels 2006, 20, 26-33.

(16) Jerndal, E.; Mattisson, T.; Lyngfelt, A. Thermal analysis of chemical-looping combustion. Chem. Eng. Res. Des. 2006, 84, 795-806.

(17) Mattisson, T.; Lyngfelt, A.; Cho, P. The use of iron oxide as an oxygen carrier in chemical-looping combustion of methane with inherent separation of CO2. Fuel 2001, 80, 1953-1962.

(18) Mattisson, T.; Jardnas, A.; Lyngfelt, A. Reactivity of some metal oxides supported on alumina with alternating methane and oxygen-application for chemical-looping combustion. Energy \& Fuels 2003, 17, 643-651.

779 (19) Adanez, J.; de Diego, L. F.; Garcia-Labiano, F.; Gayan, P.; Abad, A.; Palacios, J. M. Selection of

780

781

782

783 oxygen carriers for chemical-looping combustion. Energy \& Fuels 2004, 18, 371-377.

(20) Jin, H. G.; Okamoto, T.; Ishida, M. Development of a novel chemical-looping combustion: Synthesis of a solid looping material of NiO/NiAl2O4. Industrial \& Engineering Chemistry Research 1999, $38,126-132$. 
(21) Mattisson, T.; Johansson, M.; Lyngfelt, A. The use of NiO as an oxygen carrier in chemicallooping combustion. Fuel 2006, 85, 736-747.

(22) Sedor, K. E.; Hossain, M. M.; de Lasa, H. I. Reactivity and stability of Ni/Al2O3 oxygen carrier for chemical-looping combustion (CLC). Chem. Eng. Sci. 2008, 63, 2994-3007.

(23) Zafar, Q.; Mattisson, T.; Gevert, B. Redox investigation of some oxides of transition-state metals $\mathrm{Ni}, \mathrm{Cu}, \mathrm{Fe}$, and $\mathrm{Mn}$ supported on SiO2 and MgAl2O4. Energy \& Fuels 2006, 20, 34-44.

790

(24) Mattisson, T.; Johansson, M.; Lyngfelt, A. Multicycle reduction and oxidation of different types of iron oxide particles - Application to chemical-looping combustion. Energy \& Fuels 2004, 18, 628-637.

(25) Bhavsar, S.; Veser, G. Bimetallic Fe-Ni Oxygen Carriers for Chemical Looping Combustion. Industrial \& Engineering Chemistry Research 2013, 52, 15342 - 15352.

794 (26) Muan, A.; Somiya, S. The system of iron oxide-manganese oxide in air. American journal of science (1880) 1962, 260, 230-240.

796 (27) Azimi, G.; Leion, H.; Rydén, M.; Mattisson, T.; Lyngfelt, A. Investigation of Different Mn-Fe Oxides as Oxygen Carrier for Chemical-Looping with Oxygen Uncoupling (CLOU). Energy \& Fuels 2012, 27, 367-377.

(28) Azimi, G.; Rydén, M.; Leion, H.; Mattisson, T.; Lyngfelt, A. (MnzFe1-z)yOx combined oxides as oxygen carrier for chemical-looping with oxygen uncoupling. Aiche J. 2013, 59, 582-588.

801

(29) Azimi, G.; Leion, H.; Mattisson, T.; Lyngfelt, A. Chemical-looping with oxygen uncoupling using combined $\mathrm{Mn}$-Fe oxides, testing in batch fluidized bed. Energy Procedia 2011, 4, 370-377.

803

804

(30) Shulman, A.; Cleverstam, E.; Mattisson, T.; Lyngfelt, A. Manganese/Iron, Manganese/Nickel, and Manganese/Silicon Oxides Used in Chemical-Looping With Oxygen Uncoupling (CLOU) for Combustion of Methane. Energy \& Fuels 2009, 23, 5269-5275.

(31) Shulman, A.; Cleverstam, E.; Mattisson, T.; Lyngfelt, A. Chemical - Looping with oxygen uncoupling using $\mathrm{Mn} / \mathrm{Mg}$-based oxygen carriers - Oxygen release and reactivity with methane. Fuel 2011, 90, 941-950.

809 (32) Lambert, A.; Delquié, C.; Clémeneçon, I.; Comte, E.; Lefebvre, V.; Rousseau, J.; Durand, B. Synthesis and characterization of bimetallic Fe/Mn oxides for chemical looping combustion. Energy Procedia 2009, 1, 375-381.

(33) Bhavsar, S.; Veser, G. Reducible Supports for Ni-based Oxygen Carriers in Chemical Looping Combustion. Energy \& Fuels 2013, 27, 2073-2084.

(34) Liang, S.; Veser, G. Mixed Lanthana/Ceria Nanorod-Supported Gold Catalysts for Water-GasShift. Catal. Lett. 2012, 142, 936-945.

(35) Fornasiero, P.; Balducci, G.; Di Monte, R.; Kaspar, J.; Sergo, V.; Gubitosa, G.; Ferrero, A.; Graziani, M. Modification of the Redox Behaviour of $\mathrm{CeO} 2$ Induced by Structural Doping with ZrO2. Journal of Catalysis 1996, 164, 173-183.

(36) Mamontov, E.; Egami, T.; Brezny, R.; Koranne, M.; Tyagi, S. Lattice defects and oxygen storage capacity of nanocrystalline ceria and ceria-zirconia. J. Phys. Chem. B 2000, 104, 11110-11116.

(37) Pengpanich, S.; Meeyoo, V.; Rirksomboon, T.; Bunyakiat, K. Catalytic oxidation of methane over $\mathrm{CeO} 2-\mathrm{ZrO} 2$ mixed oxide solid solution catalysts prepared via urea hydrolysis. Appl. Catal. A-Gen. 2002, 234, 221-233.

(38) Zhu, T. L.; Flytzani-Stephanopoulos, M. Catalytic partial oxidation of methane to synthesis gas over Ni-CeO2. Appl. Catal. A-Gen. 2001, 208, 403-417.

(39) de Medeiros, S. N.; Luciano, A.; Cótica, L. F.; Santos, I. A.; Paesano Jr, A.; da Cunha, J. B. M. Structural and magnetic characterization of the ball-milled $\alpha-\mathrm{Fe} 2 \mathrm{O} 3-\mathrm{Mn} 2 \mathrm{O} 3$ and $\alpha-\mathrm{Fe}-\mathrm{Mn} 2 \mathrm{O} 3$ systems. Journal of Magnetism and Magnetic Materials 2004, 281, 227-233.

831 Springer-Verlag: New York, 1975. 
(41) Geller, S. Structure of [alpha]-Mn2O3, (Mn0.983Fe0.017)2O3 and (Mn0.37Fe0.63)2O3 and relation to magnetic ordering. Acta Crystallographica Section B 1971, 27, 821-828.

(42) Seifu, D.; Kebede, A.; Oliver, F. W.; Hoffman, E.; Hammond, E.; Wynter, C.; Aning, A.; Takacs, L.; Siu, I. L.; Walker, J. C.; Tessema, G.; Seehra, M. S. Evidence of ferrimagnetic ordering in FeMnO3 produced by mechanical alloying. Journal of Magnetism and Magnetic Materials 2000, 212, 178-182.

(43) Arjmand, M.; Azad, A.-M.; Leion, H.; Lyngfelt, A.; Mattisson, T. Prospects of Al2O3 and MgAl2O4Supported CuO Oxygen Carriers in Chemical-Looping Combustion (CLC) and Chemical-Looping with Oxygen Uncoupling (CLOU). Energy \& Fuels 2011, 25, 5493-5502.

(44) Arjmand, M.; Keller, M.; Leion, H.; Mattisson, T.; Lyngfelt, A. Oxygen Release and Oxidation Rates of MgAl2O4-Supported CuO Oxygen Carrier for Chemical-Looping Combustion with Oxygen Uncoupling (CLOU). Energy \& Fuels 2012, 26, 6528-6539.

(45) Leion, H.; Mattisson, T.; Lyngfelt, A. Using chemical-looping with oxygen uncoupling (CLOU) for combustion of six different solid fuels. Energy Procedia 2009, 1, 447-453.

(46) Mattisson, T.; Leion, H.; Lyngfelt, A. Chemical-looping with oxygen uncoupling using $\mathrm{CuO} / \mathrm{ZrO} 2$ with petroleum coke. Fuel 2009, 88, 683-690.

(47) Mattisson, T.; Lyngfelt, A.; Leion, H. Chemical-looping with oxygen uncoupling for combustion of solid fuels. Int. J. Greenh. Gas Control 2009, 3, 11-19.

(48) Moldenhauer, P.; Rydén, M.; Mattisson, T.; Lyngfelt, A. Chemical-looping combustion and chemical-looping with oxygen uncoupling of kerosene with $\mathrm{Mn}$ - and Cu-based oxygen carriers in a circulating fluidized-bed 300\&\#xa0;W laboratory reactor. Fuel Processing Technology 2012, 104, 378389.

(49) Rydén, M.; Lyngfelt, A.; Mattisson, T. CaMn0.875Ti0.12503 as oxygen carrier for chemicallooping combustion with oxygen uncoupling (CLOU) - Experiments in a continuously operating fluidizedbed reactor system. Int. J. Greenh. Gas Control 2011, 5, 356-366.

(50) Rydén, M.; Lyngfelt, A.; Mattisson, T. Combined manganese/iron oxides as oxygen carrier for chemical looping combustion with oxygen uncoupling (CLOU) in a circulating fluidized bed reactor system. Energy Procedia 2011, 4, 341-348.

(51) Bhavsar, S.; Najera, M.; Solunke, R.; Veser, G. Chemical looping: To combustion and beyond. Catal. Today 2014, 228, 96-105.

(52) Noorman, S.; Annaland, M. V.; Kuipers, H. Packed bed reactor technology for chemical-looping combustion. Industrial \& Engineering Chemistry Research 2007, 46, 4212-4220.

(53) Solunke, R. D.; Veser, G. Hydrogen Production via Chemical Looping Steam Reforming in a Periodically Operated Fixed-Bed Reactor. Ind. Eng. Chem. Res. 2010, 49, 11037-11044. 